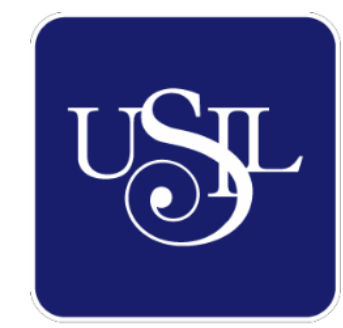

UNIVERSIDAD

SAN IGNACIO

DE LOYOLA

FACULTAD DE HUMANIDADES

Carrera de Arte y Diseño Empresarial

\title{
DISEÑO DE RED SOCIAL PARA LA DIFUSIÓN DE OPORTUNIDADES LABORALES INCLUSIVAS CONTRIBUYENDO CON EL AUMENTO DE POSIBILIDADES DE CONTRATACIÓN DE MUJERES JÓVENES TRANS DEL PERÚ
}

Tesis para optar el Título Profesional de Licenciado en Arte y Diseño Empresarial

GIOVANNA GRAZIELA FERRANDO CÁCERES

Asesor:

Rafael Vivanco Alvarez

\author{
Lima - Perú
}

2020 


\section{Dedicatoria}

Dedico esta tesis a toda mi familia Ferrando Cáceres en los que siempre recibí su apoyo incondicional, a los especialistas que me aportaron con su conocimientos, en especial al brigadier sub oficial Bejarano quien falleció durante la realización de esta investigación producto de su participación en el cuidado de la ciudadanía por motivos del estado emergencia por pandemia y me brindó información valiosa, También quiero dedicar esta investigación a todas las mujeres trans del Perú que hasta el día de hoy siguen luchando para que se les reconozca sus derechos fundamentales como el derecho al reconocimiento de su identidad, deseando que esta situación mejore, un agradecimiento especial a Leyla Huertas y

Lesly Quispe , miembros del, colectivo de mujeres trans Féminas gracias por enseñarme tanto a través de sus testimonios y mostrarme toda la valentía, y la capacidad admirable de liderar proyectos sociales. 
Agradecimientos

Quiero agradecer a mi enamorado y amigos que siempre estuvieron para darme un soporte emocional en todo momento y logramos en conjunto sobrellevar esta época difícil para el Perú y en el mundo. Agradecer también a todos los jóvenes y pobladores del Perú que a pesar de que en el Perú existía una crisis sanitaria y política, salieron a las calles para marchar por un Perú mejor y sin corrupción. 


\section{Resumen}

Las mujeres trans en el Perú llevan años sufriendo una serie de violencias terminando en algunos casos con consecuencias devastadoras para su integridad física y emocional, debido entre muchas causas a la exclusión social de la que son víctimas. Esta violencia y exclusión por ejemplo se refleja en la dificultad para acceder a una educación de calidad que le permita un trabajo digno permitiéndole acceder a una calidad de vida respetable.

Es así que se observa que a pesar de la existencia de iniciativas por parte de organizaciones no gubernamentales que apoyan y capacitan a diferentes organizaciones proveedoras de empleo sobre la aplicación de políticas de no discriminación y de inclusión estas no llegan a ser suficientes, reflejándose en la casi nula aceptación de empleadas transgénero en diversos sectores de la mediana y micro empresa; incluso en las grandes corporaciones su presencia es casi nula.

Es así que se diseña una red social con una visión más inclusiva y de igualdad de oportunidades que ofrece una oferta laboral más amplia y con mayores criterios de equidad. Para lograr mayores posibilidades de empleo, se ha destinado dirigir este proyecto a los nuevos emprendedores de pequeñas o medianas empresas que estén buscando nuevos talentos para incluirlos en sus equipos de trabajo y que al unirse a la red social logren ser sensibilizados por medio de capacitaciones virtuales se fomente la visión de equidad e inclusión.

Palabras clave: transgénero, transexual, diseño gráfico, empleabilidad, inclusión 


\begin{abstract}
Trans women in Peru have been suffering a series of violence for years, ending in some cases with devastating consequences for their physical and emotional integrity, due among many causes to the social exclusion of which they are victims. This violence and exclusion, for example, is reflected in the difficulty of accessing a quality education that allows them a decent job allowing them to access a respectable quality of life.

Thus, it is observed that despite the existence of initiatives by non-governmental organizations that support and train different employment provider organizations on the application of non-discrimination and inclusion policies, these are not sufficient, reflecting on the almost zero acceptance of transgender employees in various sectors of medium and microenterprises; even in large corporations, their presence is almost nil.
\end{abstract}

Thus, a social network is designed with a more inclusive vision and equal opportunities that offers a wider job offer and with greater criteria of equity. To achieve greater employment opportunities, this project has been aimed at new entrepreneurs of small or medium-sized companies who are looking for new talents to include them in their work teams and who by joining the social network can be sensitized through training the vision of equity and inclusion is promoted.

Keywords: transgender, transsexual, graphic design, employability, inclusion 


\section{Índice}

Capítulo I 99

$\begin{array}{ll}\text { Introducción. } & 9\end{array}$

Descripción del Problema Encontrado. $\quad 11$

$\begin{array}{ll}\text { Problema principal. } & 12\end{array}$

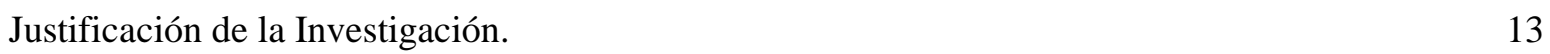

$\begin{array}{ll}\text { Pregunta de investigación. } & 14\end{array}$

$\begin{array}{ll}\text { Hipótesis. } & 14\end{array}$

Capítulo II $\quad 15$

$\begin{array}{ll}\text { Análisis de los Actores. } & 15\end{array}$

$\begin{array}{ll}\text { Mujer Trans. } & 15\end{array}$

$\begin{array}{ll}\text { Padres que apoyan. } & 16\end{array}$

Padres que no apoyan. $\quad 16$

Amigos. 16

$\begin{array}{ll}\text { Amigos Trans. } & 17\end{array}$

$\begin{array}{ll}\text { El Congreso. } & 17\end{array}$

$\begin{array}{ll}\text { Poder Judicial. } & 17\end{array}$

$\begin{array}{ll}\text { RENIEC. } & 18\end{array}$

$\begin{array}{lr}\text { Área de capital humano de una Empresa. } & 18\end{array}$

$\begin{array}{ll}\text { Consumidor. } & 18\end{array}$

$\begin{array}{lr}\text { Empresas. } & 19\end{array}$

Psicólogo Clínico. $\quad 19$

Ministerio de Trabajo y Promoción del Empleo. 19

Metodología del problema. 20

Encuestas Cuantitativas. 20

$\begin{array}{ll}\text { Entrevistas. } & 20\end{array}$

Registro Audiovisual. $\quad 21$

Metodología del proyecto. $\quad 21$

Público Objetivo. $\quad 21$

Capitulo III 22

$\begin{array}{ll}\text { Identidad. } & 22\end{array}$

Identidad Personal. $\quad 22$

Identidad Social. $\quad 22$

Identidad de género. $\quad 23$

Disforia de género. $\quad 23$ 
Transexualidad.

Transgénero 24

Cisgénero. $\quad 25$

Trabajo. $\quad 25$

Requisitos laborales. $\quad 25$

Educación. $\quad 25$

Documentación. $\quad 26$

$\begin{array}{ll}\text { Trabajo formal. } & 27\end{array}$

$\begin{array}{ll}\text { Trabajo informal. } & 27\end{array}$

Oportunidades laborales en el Perú. $\quad 27$

Reclutamiento. 28

Entrevista. $\quad 28$

Selección. $\quad 29$

$\begin{array}{lr}\text { Marco Legal. } & 29\end{array}$

Sueldo mínimo en el Perú. $\quad 29$

Beneficios laborales. $\quad 30$

Oportunidades laborales para personas trans. 31

Oportunidades laborales para personas LGBTIQ. $\quad 32$

Discriminación de género 32

Causas. $\quad 34$

Consecuencias.

Depresión. $\quad 35$

Ansiedad. $\quad 36$

Opciones finales para una mujer trans. 36

$\begin{array}{ll}\text { Causas. } & 37\end{array}$

$\begin{array}{ll}\text { Consecuencias. } & 37\end{array}$

$\begin{array}{ll}\text { Calidad de Vida. } & 38\end{array}$

$\begin{array}{ll}\text { Áreas. } & 38\end{array}$

$\begin{array}{ll}\text { Bienestar físico. } & 38\end{array}$

Bienestar Emocional. $\quad 38$

Bienestar material. $\quad 38$

Derechos Humanos. 39

Redes Sociales. $\quad 39$

Tipos de Redes sociales.

$\begin{array}{ll}\text { Capitulo IV } & 42\end{array}$

Público Objetivo. $\quad 42$ 
Concepto.

Moodboard.

Paletas de color.

Tipografías

Proyecto de diseño

1era etapa. Campaña de lanzamiento

2da etapa: Taller gratuito y exploración de la Red social

Relación entre problema, público objetivo y proyecto

Marca del proyecto

Reflexiones

62

Conclusiones

62

Anexos

64

Bibliografía 


\section{Introducción.}

\section{Capítulo I}

Dentro de La comunidad de lesbianas, gays, bisexuales, transexuales, intersexual y queer del Perú, conocido por las siglas LGBTIQ, se puede encontrar al grupo de mujeres transexuales y transgénero. Estas mujeres llevan años sufriendo violencias estructurales, este tipo de violencia se refiere a todas aquellas acciones o situaciones propiciadas por un causante no necesariamente especificado, que pone en vulnerabilidad los derechos humanos de una persona y/u obstaculizan el acceso a los recursos que ayudan a cubrir sus necesidades básicas, utilizando como sustento, leyes o normas que los ayudan a auto beneficiarse y tomar provecho de la otra persona (Machuca, Cocchella \& Gallegos, 2016). En el Perú actualmente las mujeres trans, siguen siendo discriminadas y son objeto de burla, abusadas, desvalorizadas, asesinadas, excluidas, etc. Realidad que está en discordancia con la mayoría de los 30 artículos que componen la declaración de los derechos humanos promulgado por la Organización de las Naciones y de la cual el Perú es firmante desde el año 1945 y cuyo artículo tercero menciona que "Todo individuo tiene derecho a la vida, a la libertad y a la seguridad de su persona" y el artículo quinto donde se menciona que: "Nadie será sometido a torturas ni a penas o tratos crueles, inhumanos o degradantes”. Estos artículos quedan finalmente como tales, un texto de buenas intenciones pero que no llegan a cumplirse en la realidad tan cruda como la peruana.

La vulneración de los derechos universales de una persona ocasiona mayores problemas que no escalan únicamente hacia el ámbito de la salud o la falta de educación, sino también de limitadas oportunidades de trabajo debido a los prejuicios y desconocimiento sobre la diversidad de identidad de género. En la entrevista efectuada a la señorita Leyla Huertas, líder activista del Colectivo de mujeres trans Féminas Perú, refiere que los estados deben invertir en la educación de las personas para poder hablar sobre un enfoque de género a todos los niveles, de esta manera se puede entender que todas las personas se deben 
respetar por quienes son, sin juzgar en función del sexo con el que se nace, debido que hablar de enfoque de género es hablar sobre personas, ya que somos diversos. (Huertas, 2020)

La llegada del virus COVID-19 al Perú y la cuarentena frenaron en gran porcentaje el trabajo sexual principal fuente de ingresos de las mujeres trans, esto debido a que la actividad es una de las pocas fuentes de ingreso que tienen para cubrir sus necesidades. Al mismo tiempo ha servido para ser visibilizadas como una población vulnerable y víctimas de discriminación, esto se evidenció en una anécdota no muy agradable que ocurrió en las primeras semanas de la pandemia cuando una de las normas publicadas establecía que los hombres podían salir determinados días y las mujeres otros, entonces surgió la pregunta ¿Dónde quedaban las personas transgéneros y tras más? Pues lo que surgió finalmente fueron actos de burlas, discriminación y vejámenes hacia las personas pertenecientes a esta minoría pocas veces visibilizada.

Se menciona en el artículo 6 B del Manual de derechos humanos aplicados a la función policial, presentado el 2018.

Las personas gays, bisexuales, transexuales e intersexuales son personas que deben ser tratadas con el mismo respeto con el que se brinda a cualquier ciudadano, evitando todo tipo de discriminación agravio a la dignidad o intimidad de la persona, además de garantizar y reconocer el derecho a la libre expresión asociación y reunión. (Ministerio del Interior, 2018 p.20)

Esta problemática nos genera ciertas preguntas, ¿Es suficiente una ley de género para amparar y crear mayores oportunidades a las mujeres transexuales? ¿De quién/es depende que se origine un cambio en el Perú con respecto a la inclusión de identidad de género? 


\section{Descripción del Problema Encontrado.}

La ausencia del reconocimiento de la identidad de género en las mujeres jóvenes transgénero limita las oportunidades laborales, debido que algunas empresas perciben esta condición como una problemática, obstáculo o desafío que implica la inversión de recursos para capacitar y sensibilizar a toda su organización y al mismo tiempo brindarle un ambiente saludable a la persona transgénero.

La ausencia de la ley de identidad de género, expone a las mujeres trans al Bullying, discriminación y rechazo que pueden manifestarse dentro de una organización, Por otro lado, muchas mujeres trans prefieren evitar pasar por estos episodios de Transfobia, que ya han experimentado incluso durante su formación académica y decidir no ser parte de comunidades laborales.

La carencia de oportunidades laborales en el Perú y poder disfrutar de todos los beneficios que implica trabajar en una organización, puede llevarlas a exponerse y ejercer actividades para sobrevivir que ponen en riesgo su integridad tanto física como mental.

Según el informe de violencia sistemática de las autoridades contra mujeres trans trabajadores sexuales en Lima del proyecto UNICXS (Anexo 1), liderado por la Universidad Peruana Cayetano Heredia, la Red Trans Perú y la Sociedad FTM Perú en nuestro país; y por la Universidad de Harvard y el Instituto Fenway en EEUU. menciona que "el $64 \%$ de mujeres transgénero en Lima recurren al trabajo sexual como principal fuente de ingreso debido a la exclusión social acceso limitado a empleo, al DNI, migración forzada entre otros. (Observatorio de derechos LGBTI y VHI/SIDA \& UNICXS, 2015).

Por el contrario, en la entrevista efectuada a la señorita Leyla Huertas, líder activista del colectivo de mujeres trans Féminas Perú afirma que en el 1er censo virtual que realizó la organización con la participación de 700 mujeres transexuales en el 2019, dio como 
resultado con respecto al tema del trabajo, que un $42 \%$ de mujeres transexuales se dedica al trabajo sexual, un $31 \%$ en trabajos informales y un $27 \%$ no trabaja.

Sin embargo, Leyla comenta que a pesar de que este censo muestre que $42 \%$ de las mujeres transexuales se dedica al trabajo sexual, esta cifra podría ser mayor, debido que algunas mujeres transexuales no ven la prostitución como un trabajo.

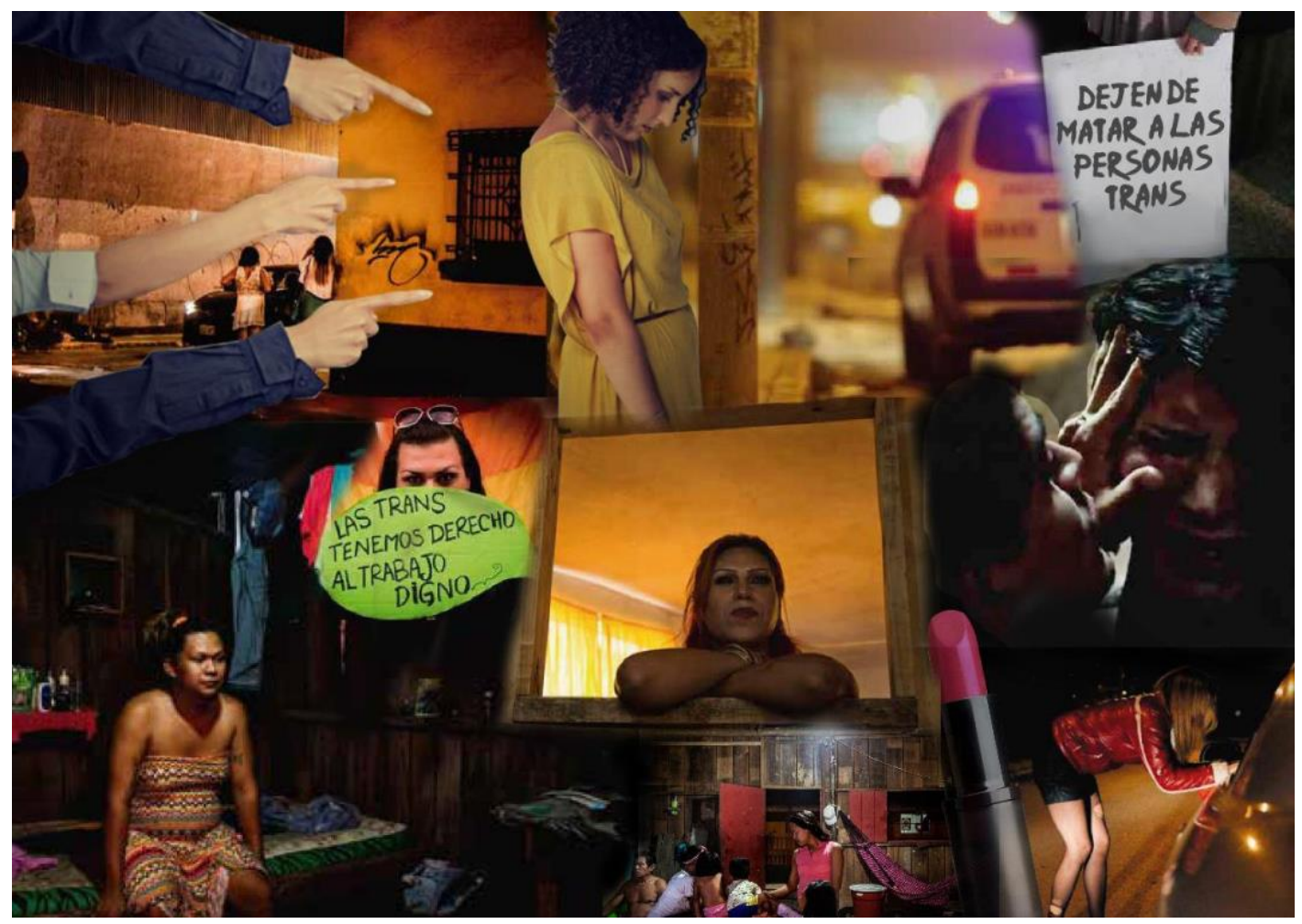

Figura 1: Moodboard del problema. Fuente propia

\section{Problema principal.}

La falta de aprobación de la ley de identidad de género en el Perú que ocasiona una carencia de oportunidades laborales en mujeres jóvenes trans.

\section{Problemas secundarios.}

Deterioro en la calidad de vida. Por la falta de aprobación de la ley de identidad de género en el Perú que ocasiona una carencia de oportunidades laborales en mujeres jóvenes trans. Aumento del riesgo personal. Por la falta de aprobación de la ley de identidad de género en el Perú, que ocasiona una carencia de oportunidades laborales en mujeres jóvenes trans. 


\section{Justificación de la Investigación.}

Las mujeres trans llevan años sufriendo de carencias en el ámbito laboral, debido a prejuicios y exclusión, por parte de las autoridades y la sociedad, sin embargo, aún no existen las suficientes normativas que frenen este tipo de trato diferenciado o amparen esta carencia. Conocer el estado actual laboral de las mujeres trans es importante para que se pueda reconocer qué o quienes están obstaculizando el libre acceso de recursos que las mujeres transexuales necesitan utilizar para cubrir sus necesidades humanas (vivienda, bienestar, libertad e identidad).

Debido al estado de emergencias que se vive por el coronavirus actualmente en el Perú, el presidente Vizcarra hizo adoptar al personal de orden público medidas de carácter inclusivo para el libre tránsito según el género que se vivió entre el 3 y 10 de abril del presente año, sin embargo, se presentaron casos de exclusión y transfobia por parte de efectivos policiales y de fuerzas armadas hacia las mujeres trans, por expresar y actuar según su identidad género. Desde el punto de vista de Leyla Huertas se puede generar una interrogante ¿De qué sirve brindar leyes o normativas a las personas si no van a querer respetarlas y cumplirlas? ¿Se debe trabajar con la educación en todos los niveles? (Huertas, 2020).

Debido a los acontecimientos de transfobia y exclusión se plantea en esta investigación brindar información que fomente el respeto hacia la diversidad de género e identidad de género, de esta manera se obtiene un conocimiento más amplio para evaluar la importancia de normativas que amparan a las mujeres transexuales y cómo en realidad aportaría a la sociedad si se les brinda oportunidades reales para formar parte de proyectos que ayudan en el desarrollo del Perú o desempeñen cargos en puestos laborales formales.

En el Perú existen ONGS y pequeñas organizaciones que se dedican a capacitar y educar empresas dispuestas a tener conocimiento sobre diversidad de género e identidad de 
género, se incluye además dentro de esta capacitación la recomendación de incluir políticas LGTBIQ dentro del reglamento interno de trabajo. Sin embargo, aún no existe data específica que corrobore la participación de mujeres transgéneros en empresas formales, lo que sí se puede afirmar es que existe un porcentaje mayor del $50 \%$ que trabajan entre puestos laborales informales y trabajo sexual.

\section{Pregunta de investigación.}

¿En qué medida la creación de una red social para la difusión de oportunidades laborales inclusivas en todos los niveles, contribuye a aumentar las oportunidades laborales en mujeres jóvenes trans del Perú?

\section{Hipótesis.}

La creación de una red social para la difusión de oportunidades laborales inclusivas en todos los niveles, contribuye en el aumento de las oportunidades laborales en mujeres jóvenes trans del Perú. 


\section{Capítulo II}

\section{Análisis de los Actores.}

\section{Mujer Trans.}

La mujer trans es aquella persona que al nacer se les asignó el sexo masculino, sin embargo, la identidad de género de esta persona es femenino, la abreviación trans se refiere e incluye a las mujeres transexuales y transgénero. Para algunas de ellas no son necesario la identificación con categoría de mujer, pero incluyen elementos de característica femenina (Machuca et al., 2016). La calidad de vida de la mayoría de mujeres trans se ve vulnerada por diferentes violencias que las rodean y por las actividades que suelen realizar para subsistir dentro de una sociedad excluyente y discriminatoria. En el Perú la mayoría mujeres trans carecen de beneficios de salud, educación y trabajo, además de sufrir el rechazo por parte de sus familiares, lo que genera en muchos casos que se alejen de su hogar o se aferren a oportunidades laborales falsas que las somete a fin de cuentas a sufrir de abusos y maltratos que al verse expuestas, desprotegidas y sin oportunidad de mejora económica , se "adaptan" a una vida que la sociedad ignora y posiciona únicamente en lugares y actividades de trabajo sexual.

A pesar de que algunas mujeres trans tienen una formación académica a costa de mucho esfuerzo familiar o de ellas mismas, las puertas laborales se cierran por diversos prejuicios que han sido posicionados en las mentes de las personas, sea por la educación o por medios masivos que dan una idea irreal de lo que significa ser una mujer trans en el Perú y lo que empuja a tener experiencias traumáticas y de limitado desarrollo personal. A raíz de la pandemia, la organización Féminas Perú liderado por la activista trans Leyla Huertas, y con el apoyo de otras organizaciones sin fines de lucro se han estado distribuyendo ayuda humanitaria para mujeres transexuales en estado de alta precariedad ya que en estos tiempos de pandemia se han podido visibilizar un poco más su situación de 
pobreza y necesidad, ya que al restringirse las actividades que las obligaban a circular las calles, no pueden actualmente sostener en algunos casos sus hogares ni a ellas mismas.

\section{Padres que apoyan.}

Los padres que viven de cerca la transición de sus hijos En un inicio pueden llegar a estar desorientados por la situación, pero luego se disponen a, aprender e incluso ir terapia si es necesario para lograr comprender que necesitan para crean un ambiente familiar que apoye a sus hijas, quienes en diferentes espacios sean virtual o real se enfrentan a una sociedad aun con muchos prejuicios. Entienden además que lo importante es trabajar en unión de todos los miembros de la familia para brindar seguridad y estabilidad a las personas que la conforman, de esta manera la personas trans puede vivir plenamente con su identidad de género.

\section{Padres que no apoyan.}

Los padres que no apoyan a sus hijos transexuales, no están de acuerdo con la expresión e identidad de género de sus hijos y no entienden sobre el proceso de transición, además son herederos de pensamientos conservadores con educación patriarcal y tradicional. $\mathrm{Su}$ postura sobre el tema se basa en creencias religiosas, como brújula para direccionar sus opiniones y argumentar que la transexualidad es una aberración y está fuera de las leyes bíblicas.

\section{Amigos.}

Son las personas que rodean el círculo cercano de la mujer transexual y comprenden la situación de prejuicio y exclusión por la que viven. Pueden llegar a ser personas que están pasando o han pasado por las mismas situaciones de discriminación y precariedad, a su vez apoyan a la mujer trans, en el proceso de transición. 


\section{Amigos Trans.}

Los amigos transgénero o transexuales son aquellas personas que entienden lo que es vivir con señalamientos, prejuicios y carencias al momento de iniciar una transición o mostrarse a la sociedad con la identidad de género con el que uno se identifican, también son aquellos que refugian a estas personas cuando han escapado de casa, como por ejemplo La casa trans Zuleymi que acoge de manera temporal a mujeres trans que están en situación de pobreza , abandono, violencia o en condición de migrantes, en este tipo de lugares se encuentra información, orientación y amigos trans que entienden la situación similar que se vive.

\section{El Congreso.}

Tiene como función principal representar a la nación, generando leyes y fiscalizando en el continuo desarrollo económico político y social del país. Sin embargo, en el caso sobre la propuesta de Ley de identidad de género aún no ha sido debatida ni revisada por el congreso generando así en las minorías que no se sientan representados por las personas que ocupan esos puestos.

Según Leyla Huertas las personas con puestos importantes en el Perú no permiten que leyes que desean beneficiar a la comunidad trans, sean escritas o aprobadas, pues siempre intentan priorizar otros temas, ignorando que este también es de suma importancia para la población del país. Por el contrario, facilitan la gestión de leyes que beneficien a su conveniencia.

\section{Poder Judicial.}

El poder Judicial es el encargado actualmente de revisar los casos y gestionar resoluciones con respecto al pedido de rectificación del nombre y la reasignación del sexo de una persona, atreves de un proceso legal que demanda argumentar la petición atreves del asesoramiento de un abogado, este proceso puede durar hasta 10 años dependiendo el 
tiempo que se deba tomar en revisar el caso, por ello el poder Judicial ha recomendado que se genere una mesa de trabajo que entre el poder ejecutivo y la RENIEC, que ayude a tramitar el proceso de cambio de nombre de manera más administrativa que judicial.

\section{RENIEC.}

Dentro del Registro Nacional de Identificación y Estado Civil, forma parte el procurador el cual actúa como defensa jurídica del Estado en diferentes ámbitos como el arbitraje y conciliaciones. En su defecto para el caso de reasignación de sexo suelen apelar en la mayoría de casos alegando que no existe normativa que regule ese requerimiento y con respecto a la rectificación de nombre, ignoran muchas veces la resolución positiva que da el juez ante el caso y en ocasiones esto alarga en mayor tiempo el proceso del cambio de nombre.

\section{Área de capital humano de una Empresa.}

Está encargado por los psicólogos organizacionales quienes son los responsables de reclutar y seleccionar a la persona más adecuada para ejercer el puesto laboral, utilizan diferentes herramientas en un sistema basado por competencias, como entrevistas o evaluaciones psicométricas, siendo franco en las oportunidades que serán brindadas en la empresa, para realizar esta tarea previamente organizan una Metodología que ayude en estas evaluaciones.

\section{Consumidor.}

El consumidor juega un rol importante en cuanto a esta problemática debido que es un factor que llega a influenciar en el momento de seleccionar personal para una empresa, debido que el consumidor y la empresa comparten en cierta medida valores y principios que pueden generar una afiliación por parte del consumidor. Sin embargo, también se puede hablar bajo esta característica, sobre la sociedad, y cuál es el rol que representa en toda esta problemática que depende de su sensibilidad con el tema o conocimiento sobre él. 


\section{Empresas.}

Las empresas son organizaciones que generan empleabilidad asalariada, previo a una contratación se considera tener como registro, una entrevista donde se conozca mejor al postulante, sin embargo en el caso de las mujeres trans, las empresas pueden llegar a sentir que contratar a una mujer trans es un gran reto, del cual muchas veces no están preparados o no han implementado con capacitación o la incorporación dentro de sus reglamentos, políticas LGBTIQ que ayuden a no dejar escapar a varios talentos que están en la búsqueda de oportunidades laborales.

\section{Psicólogo Clínico.}

El psicólogo Clínico, puede ser participe en el proceso de autopercepción en cuanto a la identidad de género de una persona, en muchos casos de índole familiar, generar terapias que ayuden a integrar aún más a la familia con los miembros que está pasando por transición con este apoyo que nace de la familia y que puede lograr aportar una contención ante las palabras o acciones que ofendan o tratan de vulnerar sus derechos como humano de una persona trans.

\section{Ministerio de Trabajo y Promoción del Empleo.}

El Ministerio de trabajo el Perú a pesar de sus intentos por crear programas que fomenten la inclusión de personas trans en los puestos laborales, es importante mencionar que deben ser más constantes estos proyectos o programas que beneficien de manera consistente la oportunidad real laboral para esta población, que merece obtener un trabajo digno y que goza de todos los beneficios que trae consigo el tener un empleo. Cabe mencionar que su misión también es velar por el estado emocional y ambiente laboral dentro del espacio de trabajo.

\section{Análisis del campo.}




\section{Metodología del problema.}

Se aplicará metodologías de observación etnográficas y análisis mediante encuestas y entrevistas, además se tomarán registros fotográficos que ayudarán en la recopilación de datos, sobre la realidad actual de las mujeres trans y su entorno.

\section{Encuestas Cuantitativas.}

Estas encuestas han sido realizadas para conocer los pensamientos o ideas que tiene la sociedad con respecto a la realidad actual de mujeres trans en el Perú y sobre el conocimiento que tiene sobre el tema de identidad de género y por lo que se viene proponiendo por el grupo Frente Amplio, como la "Ley de Identidad de Género". Las personas encuestadas oscilan entre los 28 y 45 años.

Además, se realizó una encuesta a nuevos emprendedores de 24 a 45 años de edad para saber su nivel de conocimiento sobre temas relacionados a la problemática, además de los criterios que toman o no en cuenta al contratar personal para su pequeña empresa.

\section{Entrevistas.}

Las entrevistas han sido realizadas a diferentes especialistas y personas que dan testimonio sobre el papel que ejercen dentro de esta problemática, de esta manera se ha podido comprender mejor quiénes y qué factores están ayudando o perjudicando en el desarrollo de la solución para el problema social que se presenta en esta investigación. Se entrevistó a la activista y líder del colectivo de mujeres trans Féminas Perú Leyla Huertas, quien ha comentado sobre los diferentes obstáculos que suelen vivir las mujeres trans en el ámbito laboral y además de los logros obtenidos como colectivo. El Máster en psicología organizacional Diego Chávez quien dio alcances sobre los diferentes procesos que se llevan a cabo en el ámbito organizacional para reclutar personal y recomendaciones sobre las acciones que las empresas pueden tomar con respecto a la problemática que se plantea en la tesis. 
El Psicólogo Clínico Diego Borja Chávez, quien comentó sobre las diferentes reacciones o emociones que podrían desarrollarse en la mujer trans al pasar por situaciones de exclusión, tomando en cuenta el contexto en el que se desarrolla y el ambiente que la rodea. La Abogada Silvana Rosales, ha brindado información con respecto al proceso cambio de nombre y género y actualmente como se está atendiendo la problemática por el lado legal. Finalmente se entrevistó a la señorita Lesly Quispe, miembro del colectivo Féminas Perú y líder de un proyecto autónomo llamado Mascarilla Solidaria Perú, el cual actualmente se destina a ayudar a comunidades Awajun de Amazonas, ha dado sus apreciaciones con respecto a la problemática que se plantea desde su perspectiva como una mujer trans capacitada y con experiencia en la búsqueda de una oportunidad laboral.

\section{Registro Audiovisual.}

El registro audiovisual, ha sido utilizado para recopilar una serie de eventos y situaciones que evidencien la problemática y ayuden a generar contrastes dentro del desarrollo de esta investigación. Este tipo de registro va ser utilizado para testimoniar experiencia que las mujeres transexuales pasan de manera cotidiana, siendo en muchas ocasiones vivencias negativas, incluso dentro de los medios digitales como redes sociales.

\section{Metodología del proyecto.}

\section{Público Objetivo.}

Nuevos emprendedores de 28 a 45 años, con medianas o pequeñas empresas. Se ha destinado dirigir el proyecto a estas personas debido a que planifican sus objetivos y la de sus empresas a corto, mediano y largo plazo, sin embargo, en el proceso se capacitan, investigan y no dejan pasar la oportunidad para ampliar su conocimiento y por lo tanto tomar mejores decisiones dentro la gestión de su empresa. Son principalmente quienes pueden proveer nuevas oportunidades laborales y a fomentar un ambiente inclusivo dentro de la organización. 


\section{Capitulo III}

\section{Identidad.}

La identidad es un concepto complejo, debido a que con el tiempo se va transformando, adaptándose al entorno y a la cultura que cada persona experimenta al vivir, sin embargo, se puede decir que la identidad se compone por una serie de valores, pensamientos y memorias, que ayudan a construir la personalidad y por lo tanto formar una manera de vivir y actuar.

Una identidad se basa en la descripción que una persona tiene de sí mismo, esta identidad se construye a lo largo del tiempo en el camino a convertirse en adulto, la persona puede diferenciar entre lo que le parece relevante o no dentro de toda la información y experiencia que recopila a lo largo de su vida. En el caso de no tener una identidad solida puede causar malestar e impide realizar las actividades diarias con regularidad (Charles, 1996).

\section{Identidad Personal.}

Es aquella que tiene cada individuo sobre sí sobre sí mismo el cual puede variar en diferentes momentos de su vida, dependiendo del contexto es decir la circunstancia y el rol que esté desempeñando o se le asigne en el momento, todas las características que componen a la persona llegan a integrarse y al unirse logran una auto mirada por lo que la persona encuentra la razón única de su existencia. (Mohanthy, 1994)

\section{Identidad Social.}

Es aquella que influye en parte el autoconcepto que tiene una persona de sí mismo debido a que se identifica con los grupos al que pertenece y los toma como referencia. Las personas son sociables y se interrelacionan con muchas otras, dependerá algunas veces de cada uno de ellos pertenecer a ciertos grupos o no, dependiendo de su personalidad, debido que al 
formar parte de un grupo social se adopta las normas y valores que se comparten entre sus miembros. Por ello se puede decir que las personas tendrán una identidad personal y varias identidades sociales. (García-Leiva, 2005).

\section{Identidad de género.}

Para el gobierno de México la identidad de género se crea a partir del concepto que tiene cada individuo sobre su persona, como ser sexual y emocional; esto tiene relación con la forma en que vive y siente su cuerpo a raíz de la experiencia personal y la interacción con otras personas en el ámbito público (Secretaría de Gobernación, 2016).

\section{Disforia de género.}

Es el sentimiento de inconformidad que una persona puede manifestar al no sentirse identificado con el género que socialmente se le fue asignado al nacer. La disforia de género se puede presentar en las personas desde temprana edad lo que hace más notorio la incomodidad y malestar, si la identidad de género está consolidada y tiene una persistencia en el tiempo, entonces se puede dar paso a iniciar tratamientos integrales que frenen este malestar, ya que en la actualidad existen tratamientos que con llevan procesos terapéuticos, que ayudan a mejorar la interacción dentro del ámbito social, bajar los niveles de dolencia psicológica y de manera estética lograr el aspecto de sexo que desea obtener (Hurtado 2015).

\section{Transexualidad.}

En la Décima Clasificación Internacional de las Enfermedades y Trastornos relacionados con la Salud Mental (CIE-10) se refiere a la Transexualidad como un anhelo de vivir y lograr ser reconocido como integrante del sexo opuesto, generalmente se acompaña con la disconformidad del sexo anatómico, y aspiración de someterse a procesos quirúrgicos u hormonales, que aporten en la transición física hacia el sexo elegido. 
Sin embargo, la OMS señaló que en la actualización del CIE-11 la transexualidad dejará de clasificarse dentro del capítulo de trastornos para pasar al capítulo de "condiciones relativas a la salud sexual" y ser referida como "Una incongruencia marcada y persistente entre el sexo experimentado de un individuo y el sexo asignado. El diagnóstico no puede asignarse antes del inicio de la pubertad. El comportamiento y las preferencias de género por sí solas no son una base para asignar el diagnóstico" (El Diario.es, 2018).

\section{Transgénero}

Las personas transgéneros, no sienten la necesidad de realizar una intervención quirúrgica de reasignación de sexo para lograr expresarse o identificarse con la identidad de género auto percibida o experimentada, debido que se sienten conforme con los geniales de nacimiento. Algunas personas transgéneras también pueden percibirse como no binarias, es decir la combinación de ambos géneros o de ninguno de ellos (Noseda,2012).

Mujer trans. son aquellas personas que nacieron con el sexo biológico masculino, sin embargo, se identifican y auto perciben con el género femenino. El grupo de mujeres trans se compone de mujeres transexuales y transgénero. Una investigación realizada en el 2016 por la asociación \#No tengo miedo, señalan que dentro la comunidad LGBTIQ, la población de mujeres trans ha vivido mayores situaciones de vulnerabilidad en su derecho a la identidad debido a que no han podido lograr nombrarse o identificarse con total libertad.

El no reconocimiento de la identidad de una mujer trans puede desatar diversas carencias en la vida de esta persona, en este caso puede darse la disminución de oportunidades laborales, vivir marginada o excluida, realizar la actividad de trabajo sexual como única alternativa para subsistir, ser explotada y ser víctima de trata de personas.

Sin embargo, desde el 2016 pueden acceder al proceso judicial para pedir que se les realice el cambio de nombre, esto como primera instancia. Si el proceso y la resolución por parte 
del juez es favorable, la persona pasar por la segunda instancia, donde el procurador del Registro Nacional de identificación y estado civil, suele apelar, muchas veces ignorando la resolución favorable que dictó el juez para que se realice el cambio de nombre, por es por ello que el 3er Juzgado Constitucional Transitorio de la Corte Superior de Justicia de Lima, ordenó en el presente año 2020 al Registro Nacional de Identificación y Estado Civil (RENIEC) implementar un procedimiento que permita el cambio de prenombres, sexo y demás datos de las personas trans e intersexuales en el Documento Nacional de Identidad (DNI) este procedimiento e debe estar listo en el plazo máximo de un año.

\section{Cisgénero.}

Es aquella persona que se siente conforme con la identidad y las expresiones de género que la sociedad espera y relaciona con el sexo que se le fue asignado al nacer. (Petrus, 2013)

\section{Trabajo.}

Para la Real academia española el trabajo significa dentro de sus diferentes enfoques a aquellas cosas que son producidas como resultado de la actividad humana. Sin embargo, también se considera que "El trabajo es el fundamento del orden social y determina ampliamente el lugar de los individuos en la sociedad. Es el principal medio de subsistencia y ocupa una parte esencial de la vida de los individuos” (Medá, 2007, p.17).

\section{Requisitos laborales.}

\section{Educación.}

La organización de las Naciones Unidas para la educación, ciencia y cultura menciona que la educación es un derecho humano primordial y que está entrelazado con muchos instrumentos internacionales en derechos humanos, como la Declaración Universal de derechos Humanos promulgada en 1948, La agenda 2030 para el desarrollo sostenible, entre otras. 
El ministerio de educación menciona que sus objetivos están direccionados a crear oportunidades para la población, debido a que su misión es garantizar una educación de calidad a todos los estudiantes del Perú, para alcanzar un desarrollo positivo y de competitividad en el país. Además de promover una sociedad que invierte en la educación de sus ciudadanos.

Sin embargo, con respecto a la educación en mujeres trans, se conoce a través de una encuesta realizada por la organización \#Notengomiedo en el año 2016 basada en 118 testimonios de mujeres trans de los diferentes departamentos del Perú. Mirar figura 2. Que existen cifras alarmantes con respecto al grado académico alcanzado por las mujeres trans.

\begin{tabular}{c|c|c|c|c|c|c|c|c|}
\hline $\begin{array}{c}\text { Primaria } \\
\text { Incompleta }\end{array}$ & $\begin{array}{c}\text { Primaria } \\
\text { Completa }\end{array}$ & $\begin{array}{c}\text { Secundaria } \\
\text { Incompleta }\end{array}$ & $\begin{array}{c}\text { Secundaria } \\
\text { Completa }\end{array}$ & $\begin{array}{c}\text { Técnico } \\
\text { Incompleta }\end{array}$ & \multicolumn{2}{c|}{$\begin{array}{c}\text { Técnico } \\
\text { Completa }\end{array}$} & \multicolumn{2}{c|}{$\begin{array}{c}\text { Universitaria Universitaria } \\
\text { Incompleta }\end{array}$ Completa } \\
Comado
\end{tabular}

Figura 2 Distribución de la población de mujeres trans según el grado de estudios alcanzado (n=118), Nuestra voz persiste. (Machuca, et al., 2016).

Como se puede observar en el cuadro el grado académico mayor alcanzado por esta población comprende la secundaria completa e incompleta y en el caso del 38,1\% de mujeres trans no han culminado los estudios escolares básicos.

\section{Documentación.}

En el Perú las empresas son muy cuidadosas para lograr contratar al personal, es por ello que requieren de documentos que ayuden a conocer e identificar quienes son las personas que podrían entrar a la organización, evitando así problemas a futuro. El abogado del Ministerio de Trabajo y Promoción del empleo Jorge Guevara menciona que los requisitos más solicitados por las empresas son los siguientes:

Antecedentes policiales y penales, Sin embargo, es cuestión de la política que maneja cada empresa, ya que no existe una ley que prohíba el requerimiento de este documento y 
tampoco que la autorice. Inclusive en algunas otras requieren el certificado médico (Perú21, 2020).

\section{Trabajo formal.}

Se le denomina trabajo formal cuando existe o se formula un contrato, que toma validez y da protección legal a un empleado, todo esto dentro de las leyes establecidas en el país. Estos trabajos sujetos a un contrato reciben beneficios tales como: jubilación, cobertura de salud familiar, seguros laborales, un sueldo establecido o fijo, aguinaldos (según la Real Academia Española, vendría a ser una bonificación o remuneración entregada a los trabajadores fuera de la paga recibida durante los doce salarios mensuales obtenidos durante el año por una celebración), licencia de maternidad, vacaciones, entre otras.

\section{Trabajo informal.}

Son empleos fuera de un marco legal sin tener de por medio un contrato tan bien conocidos como trabajo ilegal. Este tipo de empleo beneficia al empleador o contratado al no estar sujeto a todos los beneficios antes mencionados, incluso puede darse el caso de despidos totalmente injustificados, sin tener alguna responsabilidad o reclamo por parte de los trabajadores, todo esto pese a ser negativo tiene una contraparte positiva puesto que las personas con pocos recursos y estudios, pueden desempeñar un empleo e incluso estudiantes y personas egresadas pueden tomar todas estas actividades como entrenamiento y desarrollo en diversas actividades.

\section{Oportunidades laborales en el Perú.}

La Organización Internacional del trabajo afirma que los empleos asalariados son todos aquellos empleos que se regulan a través de un contrato explícito o implícito la remuneración por ser realizados. Para que esto suceda es necesario un empleado al cual se define como el trabajador que labora dentro de un empleo asalariado, también se menciona 
que los empleados con contratos estables son aquellos que han tenido o siguen teniendo un contrato con las características ya antes mencionadas.

En contraste se refiere a los empleadores como aquellos trabajadores que trabajando de manera individual o colectiva tienen un empleo definido como " empleo independiente " y que además por esta misma razón tienen las condiciones para contratar a una o varias personas que formen parte de su empresa.

En el Perú, según el reporte de la INEI en el año 2019 la tasa de desempleo en Lima entre octubre y diciembre fue de 6.6. \%, el cual ha sido la tasa más baja de los últimos tres años, también se informa en este reporte que las mujeres son la mayor parte de la población que está en búsqueda de un puesto laboral en la capital representadas con la cantidad de 191 mil 500 comparación de los 154 mil 700 varones que también fueron en busca de oportunidades laborales.

\section{Reclutamiento.}

Se entiende por reclutamiento y selección de personal al proceso de contratación que una empresa atraviesa para lograr hallar al personal idóneo que ocupe los puestos de trabajo requerido, este proceso es indispensable para lograr que la empresa sea competitiva dentro del mercado (Adecco, 2018).

\section{Entrevista.}

Según señala la empresa multinacional Adecco, la entrevista laboral es el escenario perfecto que ayuda a destacar las fortalezas de una persona y proyectarla como el mejor candidato para asumir el cargo que está postulando.

Las entrevistas forman parte del proceso de selección basada en competencias, es por ello que es considerada de gran importancia esta etapa para el reclutamiento y para los psicólogos organizacionales. 


\section{Selección.}

El propósito de la selección de personas es identificar dentro de los postulantes, quién es el más idóneo para asumir el cargo laboral de manera eficaz, aportando para el logro de objetivos y metas que tiene la organización. El sistema basado en competencias es un proceso apropiado para lograr la selección. (Gil, 2007).

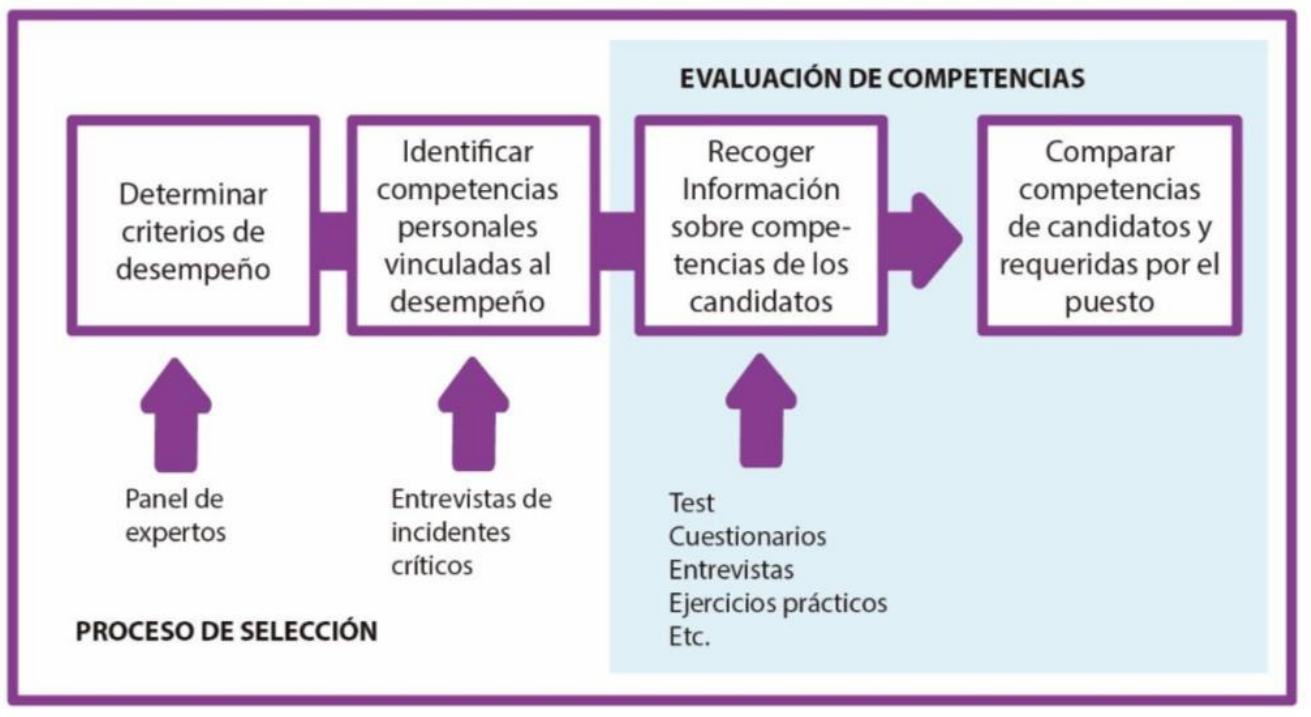

Figura 3 Lugar de la evaluación en la selección basada en competencias. (Gil, 2007)

La selección por evaluación de competencia tiene como propósito recopilar información a través de las diferentes herramientas que son utilizadas luego para mostrar todos los resultados de los candidatos ante las personas que ejercen este cargo con mayor experiencia que entra en comparación con las competencias que se necesitan para ejercer el cargo laboral.

\section{Marco Legal.}

\section{Sueldo mínimo en el Perú.}

Según el Instituto Peruano de Economía describe al salario mínimo como un pago mensual que recibe legalmente una persona por laborar ocho horas en el día, esto también está avalado por la Constitución del Perú y mencionado en la OIT. Existe rubros profesionales 
que, por la característica de su realización y respaldo por ley, tienen un sueldo superior mínimo en comparación al resto de personas, en este caso los colaboradores con horarios nocturnos, personas que trabajan en el ámbito agrario o minería.

Actualmente en el Perú el salario mínimo es de novecientos treinta soles, esto ha sido establecido en el 2018, a través de los 10 últimos años el sueldo ha aumentado trescientos ochenta soles. (RPP Noticias, 2020)

\section{Beneficios laborales.}

Según el Ministerio de trabajo y promoción del empleo del Perú, los derechos laborales más comunes en el régimen laboral general y especial del micro y pequeña empresa involucra que cada uno de los colaboradores de la actividad privada goce de una remuneración mínima vital. En cuanto a la jornada laboral tiene que llevarse a cabo como máximo 48 horas a la semana es decir 8 horas cada día, con derecho a un horario para tomar sus alimentos y descanso semanal obligatorio, licencia pre- natal y post Natal, Licencia por paternidad y vacaciones truncas.

Existen otros beneficios laborales indispensables como el seguro de salud, asignación familiar, que de acuerdo al régimen laboral que pertenece el colaborador será aplicado de diferente manera, sin excluir o limitar el goce de este debido que son prioritarias en el bienestar de cada persona y miembros que componen la familia del colaborador. Las organizaciones que ponen en práctica políticas inclusivas LGBTIQ pueden llegar a ser espacios en el que personas de la comunidad sientan que sus derechos son respetados y a pesar de la carencia legal sobre el reconocimiento a su identidad de género, las empresas pueden manejar la dinámica interna de su organización, para ello se establecen estas políticas que no afecten al trabajador ni al consumidor o cliente. La empresa Miss Cup cake es una organización dirigida al rubro de la pastelería desde el año 2009, esta empresa fue evaluada por el equipo de trabajo Presente, el cual menciona en su investigación que la 
empresa pastelera mantiene una motivación reflejada en el apoyo no solamente hacia comunidad LGBTIQ sino también a las poblaciones más vulneradas, mediante campañas en redes sociales, donaciones y visibilizarían de la comunidad de manera conmemorativa; la empresa señala también que al tener estas políticas implementadas en las organizaciones ayudan a la igualdad de oportunidades para dicha comunidad sin descuidar la existencia normativas que ayuden de manera administrativa a no permitir cualquier hecho de discriminación, finalmente se concluye que Miss Cup cake es una empresa inclusiva que aporta, celebra y no restringe la diversidad de género y de la sexualidad de sus colaboradores o postulantes, aumentando así de manera pública la apertura y posibilidad de que se sigan sumando a sus grupos de trabajo, personas de la comunidad (Gómez,2019).

\section{Oportunidades laborales para personas trans.}

En el caso de los hombres trans se observa una dificultad para obtener una oportunidad laboral o permanecer por largo tiempo dentro de una organización debido a la constante discriminación y no reconocimiento de su identidad, además de la constante complicación generar lazos de amistad o integración con sus compañeros de trabajo por su ser trans. (Gómez,2019).

Las mujeres trans, llevan muchos años arrastrando una cadena de violencias estructurales que las posiciona en una total vulnerabilidad, debido que al no tener una educación de calidad bajan las posibilidades de oportunidades laborales y aumenta el riesgo personal por realizar trabajos que atentan contra su salud física y/o mental. Existen mujeres trans que a pesar de un escenario desalentador tienen preparación académica y están en capacitación constante para apoyar en estudios e investigaciones que aporten en la lucha del reconocimiento de sus derechos e implementación de normativas que las protejan o amparen, a pesar del gran potencial que se puede encontrar en varias de las mujeres trans, muchas veces esperan la llamada que nunca llega por parte de las organizaciones a las que 
postularon, pasando por esto, la prostitución, la peluquería y oficios menores son algunas de las ultimas opciones que deciden tomar mucha mujeres trans, guiadas al fin al cabo por la marginación social.

\section{Oportunidades laborales para personas LGBTIQ.}

El Informe de la primera Encuesta Virtual para personas LGBTIQ del Instituto Nacional de Estadística e Informática conocido por sus siglas INEI, el 40 \% de trabajadores LGBTIQ sienten miedo de manifestar su género y que han interiorizado la violencia como algo normal. Además, se señaló en este informe que el $61.8 \%$ de los participantes trabaja, dentro del total de personas LGBTIQ activas en el ámbito laboral el 69,5\% trabaja de colaborador, el 17,5\% trabaja de forma independiente y finalmente el $3.2 \%$ como proveedor de empleo.

Sin embargo tal como menciona la empresa Presente en su investigación "Políticas, prácticas y retos para la inclusión de la diversidad LGBTIQ en tres centros laborales de Lima metropolitana", la carencia de estudios e interés por la condición laboral de las personas pertenecientes a dicha comunidad ha llevado a que Organizaciones no gubernamentales como PROMSEX participe en la inclusión de ordenanzas relacionadas al trabajo, una de estas ordenanzas prohíbe obstaculizar o limitar la oferta laboral por motivo de orientación Sexual.

\section{Discriminación de género}

Según la defensoría del pueblo del Perú, la discriminación significa tratar a una persona o un grupo humano de manera diferenciada o desigual. Este tipo de trato no tiene justificación ni respaldo jurídico, de hecho, va en contra de lo que ordena la ley dentro de muchos ámbitos.

Los tipos de discriminación presentadas en el ámbito social son: la xenofobia, discriminación a personas con discapacidad o alguna enfermedad, diferencia de estrato 
social, discriminación por religión, discriminación por ser mujer y la homofobia (Cota \& García, 2009).

En el caso de las personas transexuales, sufren de discriminación por transfobia, podemos describir este tipo de discriminación por las diferentes actitudes, comportamientos y sentimientos que van dirigidos hacia las personas trans de manera negativa, basándose o justificando los actos, por la expresión de la identidad de género de esta persona (Whittle, Turner y Alami, 2007). Las personas transexuales pueden llegar a sufrir también de homofobia debido a que el concepto de identidad de género y orientación sexual suele combinarse al momento de discriminar a una persona trans. (Molina, Guzmán \& Martínez, 2015).

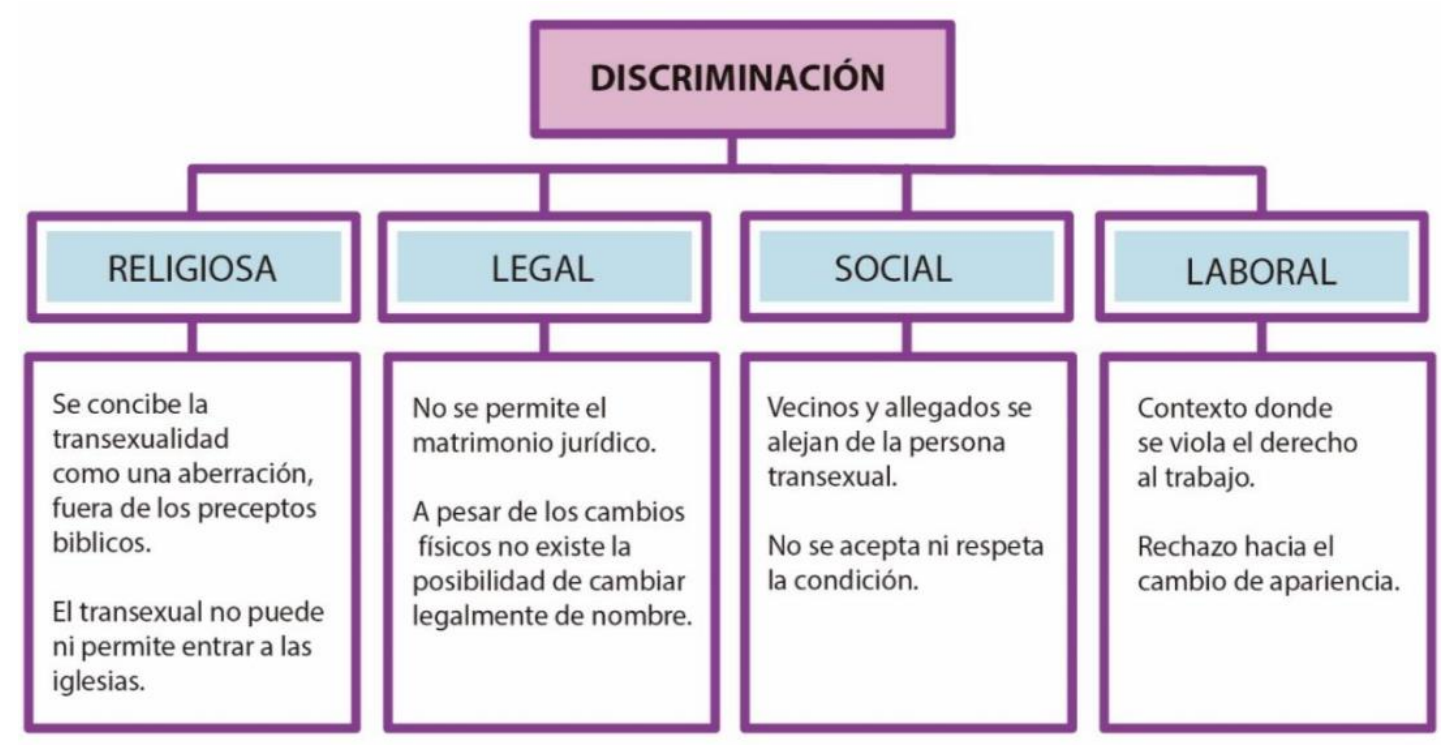

Figura 4 Estigmatización en transexuales. (Juarez,2015)

Los actos de discriminación o rechazo hacia las personas trans puede reflejarse en los diferentes ámbitos de la vida de estas personas, debido que la gente sigue teniendo prejuicios y estigmas sobre la transexualidad. Esta realidad limita el libre desarrollo personal y profesional de la población trans. 


\section{Causas.}

Abuso de autoridad. se considera Abuso de posición de poder, cuando una persona utiliza su posición para librarse totalmente de los cargos de violencia que ha perpetrado o tiene intenciones de perpetrar hacia una persona, pensando que este cargo le permite realizar este acto sin ninguna repercusión, podemos encontrar estos tipos de perpetradores en el ámbito religioso, puede ser educadores, jefes o jefas, psicólogos, médicos o todo aquel que tenga un puesto superior a la persona violentada.

Según el informe 2019 del Observatorio Nacional de derechos LGBTIQ, encontraron mayores casos de vulneración por parte de funcionarios y trabajadores del estado hacia mujeres trans, además de empleados y trabajadores del sector privado. Mirar figura 5.

\begin{tabular}{|c|c|c|c|c|c|c|c|}
\hline $\begin{array}{l}\text { POBLACIÓN } \\
\text { No DE CASOS } \\
\text { PERPETRADORES }\end{array}$ & Lésbica & Gay & $\begin{array}{c}\text { Trans } \\
\text { femenina }\end{array}$ & $\begin{array}{c}\text { Trans } \\
\text { masculino }\end{array}$ & No binaría & $\begin{array}{l}\text { Afectaciones } \\
\text { colectivas }\end{array}$ & $\begin{array}{c}\text { Total de } \\
\text { vulneraciones }\end{array}$ \\
\hline $\begin{array}{l}\text { Funcionarios y } \\
\text { trabajadores del } \\
\text { Estado }\end{array}$ & 2 & 15 & 43 & 1 & 2 & 2 & 65 \\
\hline $\begin{array}{l}\text { Empleadosy } \\
\text { trabajadores del } \\
\text { sector privado }\end{array}$ & 3 & 7 & 11 & 2 & 1 & 1 & 25 \\
\hline $\begin{array}{l}\text { Perpetradores } \\
\text { con mayor o } \\
\text { menor relación } \\
\text { con la victima }\end{array}$ & 11 & 21 & 12 & 7 & 3 & & 54 \\
\hline $\begin{array}{l}\text { Perpetradores } \\
\text { ajenos a la vida } \\
\text { de la victima }\end{array}$ & 2 & 11 & 7 & & 4 & 2 & 26 \\
\hline CASOS TOTALES & 18 & 54 & 73 & 10 & 10 & 5 & 170 \\
\hline
\end{tabular}

Figura 5. Cuadro de cruces de perpetradores con grupos poblacionales. (Silva, A. et al. 2020)

Agresión Verbal. la agresión verbal se produce por medio de insultos, amenazas, críticas, agresiones o gritos. Tolerar este tipo de agresión perjudica de manera importante a las personas violentadas. Según el licenciado en psicología y máster en recursos humanos Juan Armando Corbin, la agresión verbal en comparación con la violencia física no es notorias a simple vista, sin embargo, dejan daños que se pueden interiorizar en la persona y que necesitan un proceso de sanación o recuperación, mediante asistencia psicológica, estos daños 
suelen pasar desapercibidos debido que el agresor puede aplicar un cierto chantaje a la persona agredida.

Agresión Física. "Es la violencia que atenta contra la integridad física de una persona" (Machuca, et al 2016). En el caso de las mujeres transexuales este tipo de violencia se manifiesta desde echarles agua para retirarlas de un lugar, golpes, hasta llegar al punto de cometerse asesinatos en contra de esta población. Mirar figura 5. por su expresión de género u orientación sexual, esto llega a ser resultado de la Homofobia o Transfobia que aún existe en la sociedad.

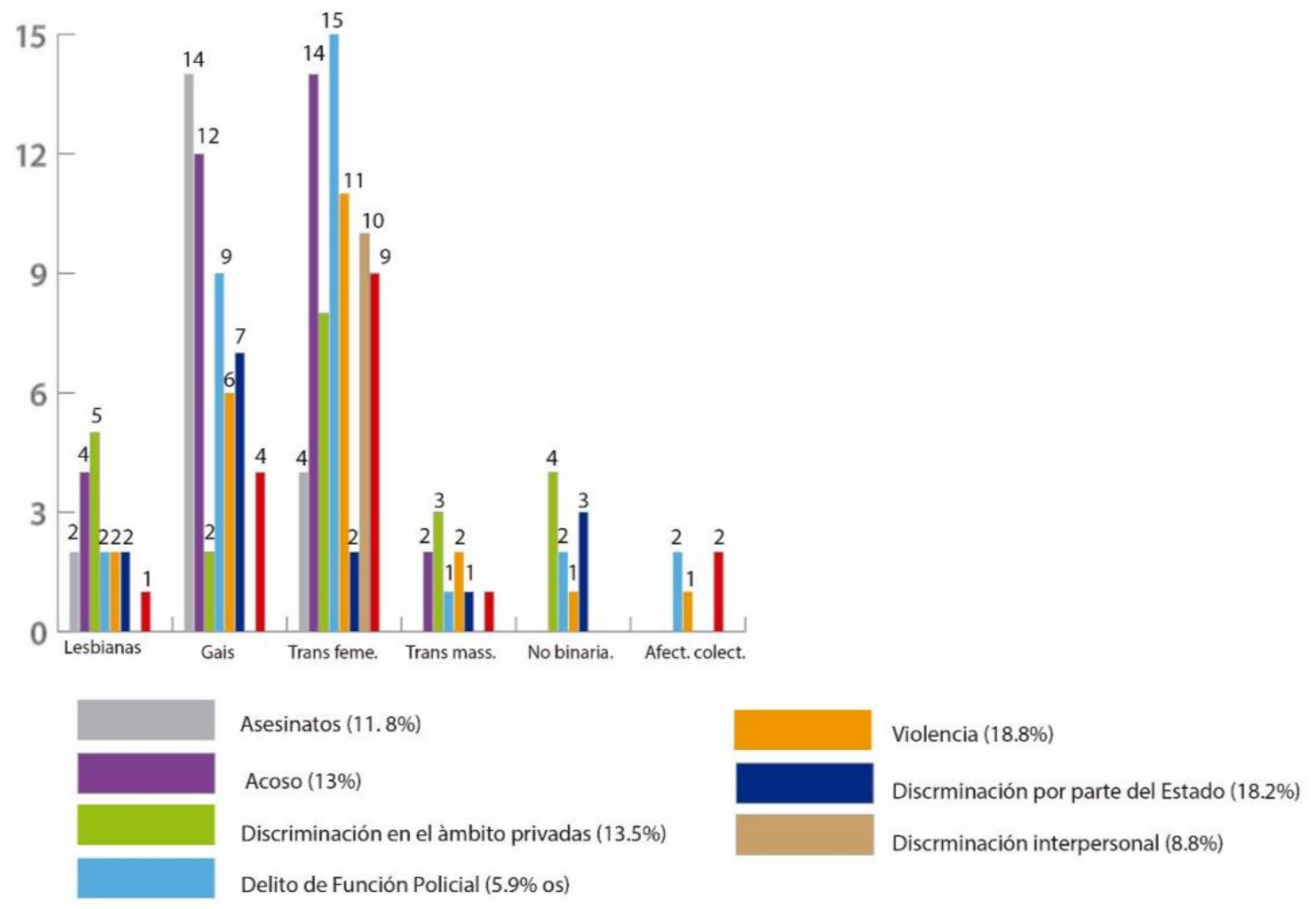

Figura 6 Vulneraciones de derechos según orientación sexual, o identidad de género. (Silva, A. et al. 2020)

\section{Consecuencias.}

\section{Depresión.}

Según el Ministerio de salud del Perú (MINSA) el trastorno depresivo, es aquella enfermedad que afecta directamente el estado de ánimo de una persona, también se conoce como trastorno del humor. Las personas que sufren de esta enfermedad llegan a sentir 
profunda tristeza, generando una apatía y desinterés de relacionarse con los demás inclusive su familia, sienten mucho cansancio al realizar una mínima acción, afecta directamente en su calidad de sueño y en la frecuencia de su apetito hacia los alimentos. De acuerdo con la Organización Mundial de la Salud (OMS) la depresión puede volverse crónica y llevar a hechos fatales como el suicidio. En el caso de ser leve es posible tratarlo con medicamentos en caso contrario si serán necesarios y acompañados siempre por un profesional en la psicología clínica.

\section{Ansiedad.}

Se origina con la activación del sistema nervioso autónomo en niveles altos que se compone de aspectos de tensión, a nivel fisiológico y que no ayudan adaptarse a las circunstancias o medios.

Por otra parte, la ansiedad puede manifestarse a través de la reacción del organismo como, tener los pies y manos fríos, mareos, aceleración cardiaca, tensión muscular e indigestión, entre otros. (Sue, 1996).

\section{Opciones finales para una mujer trans.}

El testimonio de una mujer trans como Gianna García En el informe anual del observatorio de derechos LGBT 2019 nos muestra una realidad latente que rodea la transexualidad, comenta que en su adolescencia conoció por primera vez a travestis quienes le recomendaron dejar los estudios secundarios y en cambio realizarse intervenciones quirúrgicas para formar un cuerpo más femenino según la concepción social, debido que la formación académica no sería algo que aporte a producir dinero, por el contrario el trabajo sexual según argumentaron las travestis son la fuente de ingresos más recurrente en el medio, haciéndole recordar constantemente a Gianna que las mujeres trans no estudian, no van a la universidad ni nada relacionado a la formación académica (García,2020).Cabe mencionar que El trabajo sexual para cubrir alguna de sus necesidades básicas, prevalece 
hasta la actualidad como una de las actividades de fuente de ingreso principales dentro de la comunidad de mujeres trans.

\section{Causas.}

La marginación y exclusión social hacia las mujeres trans muchas veces empieza dentro del núcleo familiar, luego se extiende dentro del ámbito educativo lo que genera en muchas mujeres trans tomar la decisión de dejar la formación académica, por lo que disminuye la posibilidad de oportunidad laboral y por lo tanto ver frustrado sus anhelos profesionales y de desarrollo personal. Los estigmas que rodean la transexualidad también forman parte de las limitadas oportunidades de desarrollo profesional en las mujeres trans debido que al no ser legalmente reconocida su identidad de género, ello puede ser considerado de manera directa o indirecta como motivo en la toma de decisiones de una empresa u organización que no está capacitada o sensibilizada con el tema, a pesar que existan recomendaciones donde se enfatiza "velar por la equidad en los procesos de reclutamiento y selección de personal, específicamente en personas trans''(OIT,2016).

\section{Consecuencias.}

La delincuencia, la prostitución o el ejercer trabajos mejores y /o estereotipados, son el resultado de las limitadas oportunidades que se le brinda a las mujeres trans, debido que al no ver una luz de esperanza optan por actividades que las ayude a sobrevivir en una sociedad que poco a poco se entera de esta realidad ignorada por muchos años, esto se refleja en la actualidad en plena pandemia y estado de emergencia, por los hechos transfóbicos llevados a cabo por autoridades ligadas al estado, sumado que al no contar con los ingresos que usualmente generaban debido al trabajo sexual, las deja en total vulnerabilidad y con menos posibilidades de llevar una vida digna. 
En los resultados de la encuesta realizada por la INEI en el año 2017 (Anexo 1) a miembros de la comunidad LGBTIQ, el $6.4 \%$ acepta haber realizado trabajo sexual por decisión personal y que el medio más utilizado para esta actividad es mediante el internet.

\section{Calidad de Vida.}

De acuerdo con la Organización Mundial de la Salud la calidad de vida significa la forma en que una persona interpreta el rol o espacio que ocupa dentro de su ambiente cultural, cuáles son los valores que tiene como referencia, sus expectativas y con todo lo relacionado planteamiento y alcanzar sus objetivos.

Se entiende por calidad de vida al nivel de bienestar personal que puede ser percibido o también llamado bienestar subjetivo

\section{Áreas.}

\section{Bienestar físico.}

Hablamos de bienestar físico cuando el cuerpo de la persona se encuentra óptimo, funciona de una manera eficiente y está preparada para responder y actuar ante algún desafío en la vida del ser humano.

\section{Bienestar Emocional.}

Es el estado de ánimo pleno en el que nos sentimos bien, calmados y capaces de sobrellevar problemas que podemos tener durante el día, teniendo como resultado un ritmo de vida más feliz y saludable.

El bienestar emocional va de la mano con los demás estados de bienestar en la persona, tales como: físico, mental, emocional, social, material y espiritual.

\section{Bienestar material.}

El bienestar material como indica el nombre, se basa en el poder de adquisición del ser humano, de sentir bienestar al poseer desde cosas básicas para subsistir (a corto plazo como el agua, electricidad, gasolina, entre otros) hasta gustos personales y propios, 
determinado por el valor laboral de la persona (proyectarse a comprar una casa o invertir en algo, a largo plazo).

\section{Derechos Humanos.}

Según las naciones unidas todos los seres humanos tienen derechos sin discriminación o nacionalidad, esto se aplica igual cuando nos referimos a orientación sexual o identidad de género.

"Todos los seres humanos nacen libres e iguales en dignidad y derechos "Carta de las naciones unidas, art.1

En el año 2011 es el Consejo de Derechos Humanos de las naciones unidas quienes aprueban una resolución sobre los derechos humanos y orientación sexual a gran escala, debido a la magnitud del problema por la violencia y discriminación: Resolución 17/19

\section{Redes Sociales.}

Se considera una red social a un sitio dentro de la web que tiene como finalidad: tener un perfil público o limitado en la red, la relación de personas, el poder comunicarse, compartir contenido y de formar comunidades o grupos de personas que tienen un interés en común.

\section{Tipos de Redes sociales.}

Debido a que las redes sociales están conformadas por la interacción de personas o grupos que tienen intereses en común, se conforman grupos enfocados, que mediante un perfil gestionan perfiles y la conexión que existe dentro del grupo.

\begin{tabular}{|c|c|c|c|}
\hline SEGÚN FINALIDAD & $\begin{array}{c}\text { SEGÚN MODO DE } \\
\text { FUNCIONAMIENTO }\end{array}$ & $\begin{array}{c}\text { SEGÚN GRADO DE } \\
\text { APERTURA }\end{array}$ & $\begin{array}{c}\text { SEGÚN NIVEL DE } \\
\text { INTEGRACIÓN }\end{array}$ \\
\hline De ocio & De contenidos & Públicas & De integración vertical \\
\hline De uso profesional & $\begin{array}{c}\text { Basada en perfiles: } \\
\text { personales/profesionales }\end{array}$ & Privadas & De integración horizontal \\
\hline & Microblogging & \\
\hline
\end{tabular}

Figura 7: Categoría de redes sociales directas en función del enfoque (ONTSI, 2011) 
Redes de trabajo. las redes de trabajo se enfocan en negocios y actividades comerciales, gestionar un perfil laboral, conseguir trabajo y tener un contacto con empresas (entorno laboral). En esta red social encontramos reclutadores o personal de recursos humanos de diversas empresas que captan y reclutan personas interesadas dependiendo el perfil que tengan, sus capacidades, estudios y el tipo de contenido en el que está involucrado.

Indeep. Es una página web que permite a los usuarios conseguir empleos y a las empresas, reclutarlos. Se crea un perfil que identifica al usuario, permite subir el Curriculum Vitae para poder postular a las ofertas laborales que tiene la página. Tiene otras funciones para la evaluación de sueldos y conocer más de las empresas mediante una clasificación o valorización.

LinkedIn. es una red social lanzada el 2003 y es la mayor red profesional a nivel mundial, cuenta con la creación de un perfil mucho más compleja que una red social, debido al número de opciones al momento de llenar el formulario, comprende tan bien diversos elementos con los que se puede mejorar el perfil del usuario, llevar clases virtuales y hacer una red de contactos amplia. Se puede usar para buscar empleo o recluta trabajadores, hay un conjunto de opciones que muestra con métricas la cantidad de postulantes y que es necesario para estar preparado frente a una entrevista laboral.

\section{Estado del Arte.}

\section{Antecedentes nacionales.}

Aliadas Trans por una atención médica oportuna. realizado en el 2019 por la alumna Cabrera Asenjo. Este proyecto intenta generar una sensibilización sobre la falta de una atención medica correcta que se destine a atender las necesidades de la población de mujeres transgénero. Para lograr este objetivo, se planteó la creación de una campaña con tres etapas, la primera consistió en crear una fan page que brinde información de instituciones que sean de 
confianza y transmitan esa amabilidad con la población. En la segunda etapa realizaron una charla informativa que abordaba temas como: derechos de salud, dificultades que suelen vivir las mujeres trans en diferentes ámbitos y diversos temas que rodean el ámbito de la salud.

Finalmente, en la tercera etapa se llevó acabo la charla que se destinó a ser meramente informativa y que al terminar se le entregó a cada persona que participó en esta charla, un kit que contenía merchandising de la campaña y productos para la prevención y acto sexual, además de folletos informativos y revista que mencionaba de forma general sobre los centros médicos públicos y privados que tiene una respetuosa y correcta atención médica para la comunidad de mujeres transgénero. Esta exposición informativa permitió que las participantes expresen su opinión sobre la charla y dar a conocer su decisión con respecto a asistir a uno de los centros médicos recomendados.

Personas Trans por la inclusión Social. realizado en el año 2016 y liderado por la Universidad Peruana Cayetano Heredia, la Red Trans Perú y la Sociedad FTM Perú y por la Universidad de Harvard y el Instituto Fenway en EEUU. Dentro de lo que promueve este proyecto es tratar con funcionarios públicos que ayuden en la planeación de políticas más inclusivas para la comunidad trans y al respeto de los derechos fundamentales. En el caso de los registros de violaciones hacia los derechos, estos casos quedan documentados en el observatorio de la universidad Peruana Cayetano Heredia y se ofrece representación legal para seguir con el caso presentado. 


\section{Capitulo IV}

\section{Público Objetivo.}

Nuevos emprendedores de 28 a 45 años de edad, dueños de medianas o pequeñas empresas. Se ha destinado dirigir el proyecto a este público debido que son principalmente quienes pueden proveer nuevas oportunidades laborales y fomentar un ambiente inclusivo dentro de la organización. Son además los encargados de plantear los valores o principios de la empresa y tomar decisiones que ayuden a lograr los objetivos de corto, mediano y largo plazo que se proponen.

Mientras se van formando y creciendo como organización u empresa este proyecto se destina a brindarles una nueva visión sobre la empleabilidad, mediante plataformas digitales que son ideales para acceder a nuevos conocimientos de manera práctica y eficaz. En los resultados de la encuesta realizada (Anexo 7) a 31 nuevos emprendedores dueños de pequeñas o medianas empresas a la pregunta ¿Consideras importante incorporar políticas inclusivas dentro de una empresa? el 51.6\% afirma que desconoce sobre las políticas inclusivas y la importancia de su aplicación en las organizaciones, esta razón los convierte en un público potencialmente dispuesto a ser informado y sensibilizarse con la problemática. Debido que el $41.9 \%$ de ellos si considera pertinente establecer políticas inclusivas en la empresa. (Ferrando, 2020)

\section{Concepto.}

Debido que la transexualidad está rodeada de estigmas y prejuicios sociales, se ha decidido proponer un proyecto bajo un concepto que refleje como en el caso de las mujeres trans o personas que experimentan estados de vulnerabilidad y violencia estructural, los deseos de superación que tienen estas personas, a pesar que muchas veces no reciban el apoyo por 
parte de sus familiares o personas cercanas han logrado salir de las calles y tomar cada pequeña posibilidad de cambio como una oportunidad de mostrar que si se puede desarrollar una persona en la vida, si uno cree en sí mismo y si se brinda es oportunidad de cambio, aquí es donde nace el concepto "Creer para crear oportunidades sin miedo, con confianza", que ayuda a connotar por parte de los nuevos emprendedores el requerimiento de un voto de confianza y de aporte al cambio, donde se aproveche el talento, las capacidades, el deseo de crecer y aprendizaje que todas las personas sin distinción anhelan en un desarrollo personal y profesional, además de proponer con este concepto un proyecto que tenga una mejor visión sobre la coherencia entre el discurso de una persona u organización con las acciones y decisiones justas que realiza anteponiendo el bienestar humano.

\section{Moodboard.}

El Moodboard ayuda a representar de manera visual el concepto, esta información de imágenes colores, formas y texturas apoyan a este proyecto recopilar elementos que ayudan o se utilizan como herramientas para transmitir el mensaje de manera eficaz y más clara, en este caso el centro de esta composición transmite en resumen lo que se espera del proyecto, que nazca y crezca la confianza las oportunidades y se vean como aliadas las mujeres transgénero, debido que como se muestra en este Moodboard son capases de asumir retos y liderar sus puestos laborales solo si se les brinda una oportunidad real. 


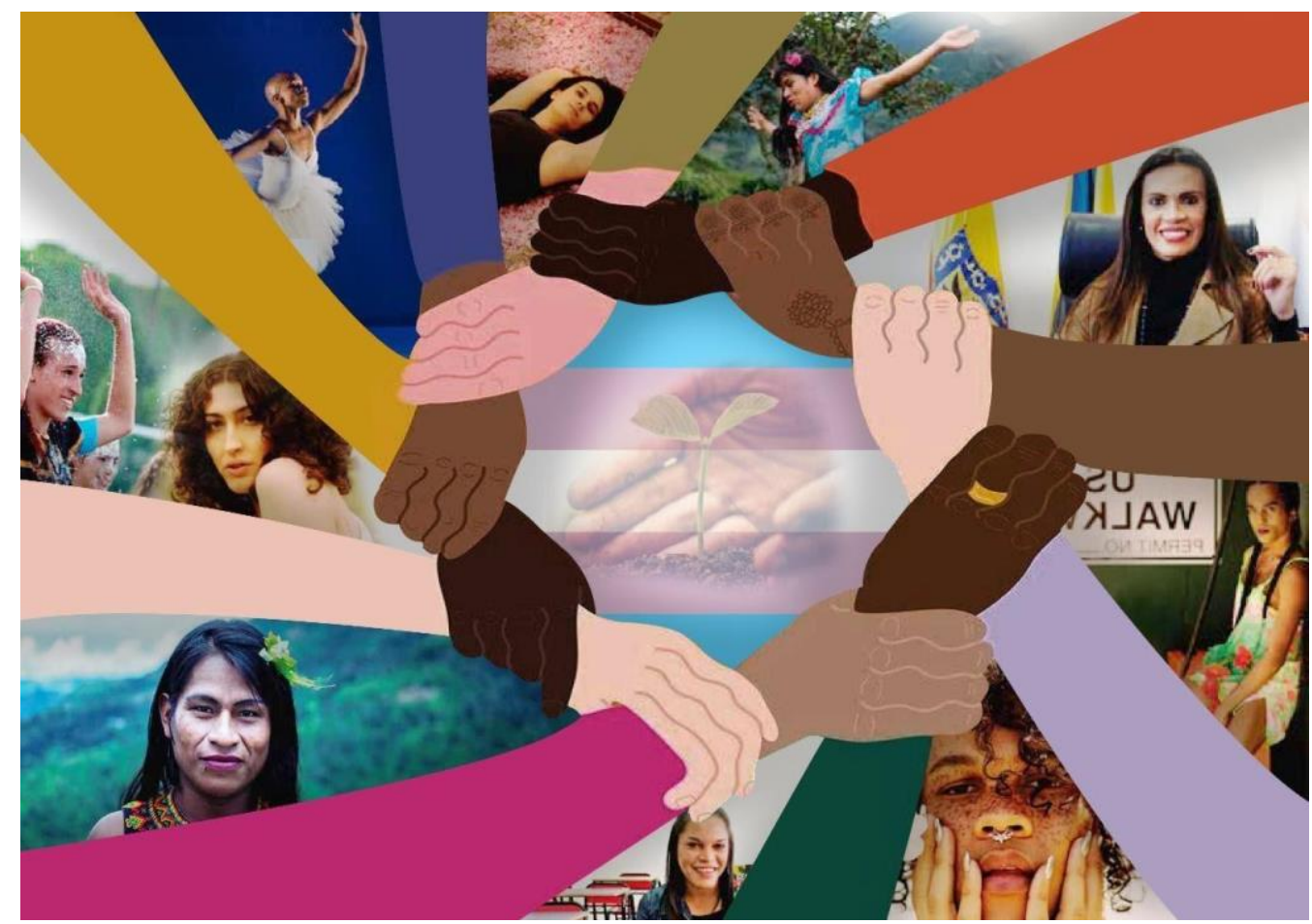

Figura 8: Moodboard del concepto. Fuente Propia

\section{Paletas de color.}

Tomando en cuenta el estudio de la psicología del color, y el concepto que debe transmitir el proyecto, se ha elegido la paleta de colores compuesto por el violeta, anaranjado y celeste. Esta combinación busca provocar reacciones y emociones positivas hacia la marca y el proyecto.

El violeta es un color de transformación en un nivel más espiritual y mental, que se relaciona directamente al cambio y a vencer miedos para generar paz. Gracias a esta asociación, es favorable el uso de este color dentro del proyecto para poder transmitir la visión del proyecto como parte de un cambio positivo.

El anaranjado es un color que suele asociarse con el entusiasmo, la alegría y diversión, lo que es ideal para incluirlo dentro de la marca y composición del proyecto debido que se destina a ser una red social y a través de ella motivar al público objetivo a ser partícipe de esta nueva filosofía de empleabilidad. 
En el caso del color celeste se le atribuye la sensación de calma y equilibrio, lo que es importante de transmitir visualmente, para lograr la tranquilidad y confianza del Público objetivo con la marca y el proyecto.
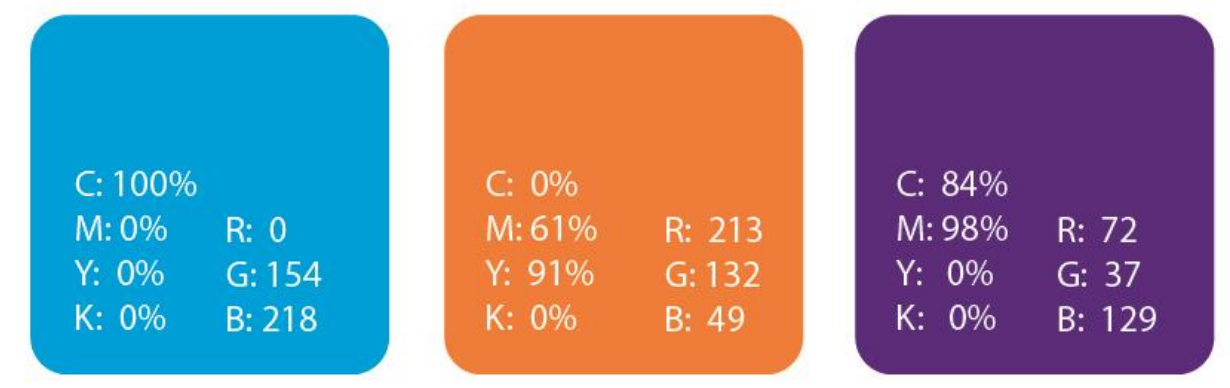

Figura 9: Paleta de colores. Fuente Propia

\section{Tipografías}

Las tipografías que se han utilizado dentro del proyecto han sido elegidas debido que sus caracteres tienen una estructura legible, simple y moderna, los cuales son ideales para ser aplicados en conjunto dentro de este proyecto digital. Las curvas en la composición de estas tipografías pueden llegar a transmitir esa parte humana sin perder el enfoque empresarial. La tipografía Museo Moderno Semibold juega un rol importante en la composición del logotipo donde al ser intervenida e interceptada por otros elementos que reflejan a todas las personas con anhelos profesionales, llega a ser la opción perfecta para resumir todo este peso conceptual.

Roboto Regular, Mayeka Bold demo regular y Myriad Pro son tipografías que se han utilizado dentro de la maquetación del proyecto debido que sus estructuras son ideales para la lectura en párrafos o textos más densos. 
Mluseonloderno SemiBold

ABCDEF G HIJKLIN N ÑOPKRS TUV WKYZ

abcdefghijk I mnñoporstuvou

$x y 2$

0123456789

Figura 10: Tipografías utilizadas según el concepto. Fuente Propia

\section{Proyecto de diseño}

Para lograr mayores oportunidades de trabajo se ha creado Laborall.org, una red social laboral que se dedica a conectar empleadores con posibles empleados, bajo la visión de la inclusión e igualdad de oportunidades. Parte importante de lo que ofrece esta plataforma virtual es la capacitación y seguimiento que se le ofrece a los nuevos emprendedores de pequeñas o medianas empresa a través de talleres, asesorías virtuales y contenido digital que servirán como herramientas para lograr aprender a ser más inclusivos y generar más valores de igualdad, y que finalmente se reflejan en las publicaciones de anuncios laborales que les permitan encontrar nuevos talentos, conseguir al personal idóneo y fortalecer la equidad y diversidad en su organización.

Esta red social además cuenta con una bolsa laboral, artículos empresariales a nivel nacional e internacional, que permite estar mejor informado sobre mundo organizacional, algunos videos cortos con recomendaciones para llevar un mejor clima laboral y un área de publicidad nativa en los que se publicarán banner con calls to action hacia las páginas de 
las empresas o especialistas aliados que aportan en el seguimiento de las empresas afiliadas y también del público objetivo que son considerados aliados también para lograr mayores oportunidades laborales. Para lograr que el proyecto se a conocer y sea funcional se han diseñado las siguientes etapas:

\section{1era etapa. Campaña de lanzamiento}

Objetivo. Atraer y registrar a nuevos usuarios (emprendedores de pequeñas o medianas empresas) dentro de la red social laboral, con el fin de experimentar de manera gratuita “el taller sobre igualdad de oportunidades y conocer los beneficios que contiene la plataforma virtual. Para lograr el objetivo de esta primera etapa se han elaborado las siguientes piezas gráficas:

A través de un mailing se enviará al público objetivo información más detallada sobre las secciones que contiene plataforma virtual, el taller gratuito de "igualdad de oportunidades" y los diferentes planes de suscripción que se ofrecerán, los cuales contienen asesorías personalizadas, talleres, campañas internas dentro de la empresa y otros beneficios que estén dentro de cada uno de los planes. También se mencionan algunas estadísticas o datos nacionales e internacionales que muestran el lado positivo de ser una empresa con visiones de igualdad de oportunidades y cuáles son las posibles mejoras que obtendrá la empresa al incluir estas buenas prácticas. El mailing también está acompañado por el video promocional y un call to action que lleve hacia la página principal de Laborall.org. 


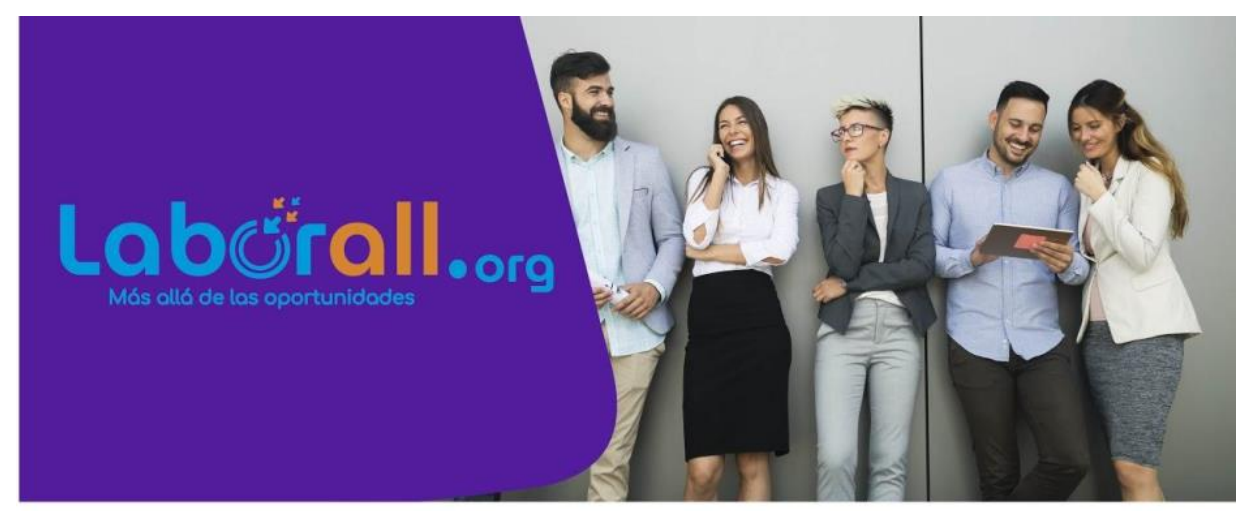

¡Hola, somos Laborall.org un nuevo

concepto sobre empleabilidad, en donde los derechos de

todos son los más importantes y van de la mano con el

respeto, la igualdad y la tolerancial.

Queremos que seas parte de esta nueva visión y en conjunto puedas crecer como una de las empresas solida, con diversidad, mayores oportunidades para sus colaboradores y con excelente rendimiento en el ambiente laboral. Para lograrlo Laborall.org te ofrece los siguientes servicios que podrás encontra

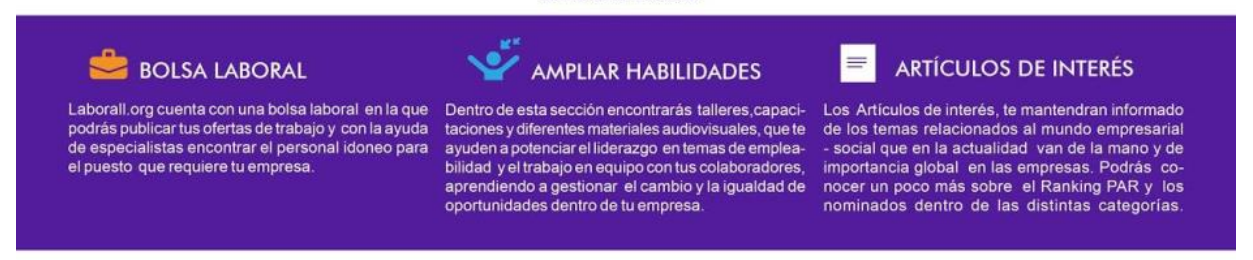

TALLER GRATUITO

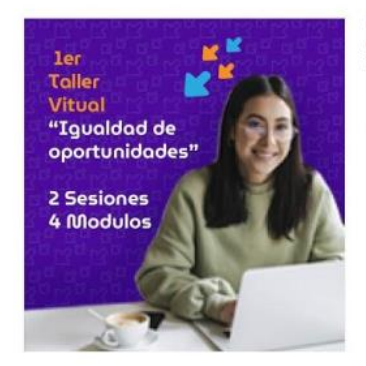

Objetivo del taller virtual. Aprender sobre los conceptos,principios y temas que rodean la igualdad de

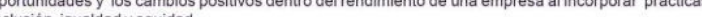

\section{Sesión 1 Cि 45 min}

Modulo 1

¿Que significa la igualdad de

Modulo 2

La igualdad de oportunidades aplicada

en ambientes laborales.

\section{Sesión $2 C_{45 \min }$}

Modulo 3

Hablemos de diversidad sin discrminación

Modulo 4

¿Porque Laborall. org más allá de las oportuni-

Registrate para asistir gratis al taller

PAQUETES DE SUSCRIPCIÓN

\section{(c)}

PAQUETE REGULAR

Adquiriendo este paquete de suscripción mensual se te Adquiriendo este paquete de suscripc
brindará los siguientes beneficios:

Proceso de selección de personal a cargo de especialistas del equipo Laborall.org bajo criterios de equidad e igualdad de oportunidades.

Asesorias para evaluar temas particulares de la empresa. ejemplo: Nivel de satisfacción de los colabol

INFORMATE MAS AQUI

\section{(ci)}

PAQUETE PREMIUM

Adquiriendo este paquete de suscripción mensual se te brindará los siguientes beneficios:

- Proceso de selección de personal a cargo de especialistas del equipo Laborali.org bajo criterios de equidad e

- Asesorias para evaluar temas particulares de la emdores en la empresa, rendimiento laboral del personal. - Creación y Diseños de campaña interna sobre diversidad,equidad e igualdad de oportunidades, entre otros. - mención publicitaria de tu empresa como aliado estrategicoy diseño de públicidad nativa dentro de la red social
Laborall org

INFORMATE MAS AQUI

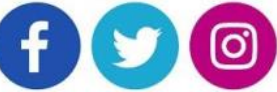


Figura 11. Mailing de Laboral.org. Fuente Propia

Las publicaciones en Facebook ayudarán a presentar a la marca dentro del medio digital, mostrando también en cada post los contenidos que tiene la plataforma y lo que ofrece al público objetivo y a los usuarios en general.

El video promocional será diseñado para dar a conocer la nueva visión que tiene Laborall.org sobre la empleabilidad, y lo que contiene la red social.

\section{2da etapa: Taller gratuito y exploración de la Red social}

Para los nuevos usuarios que se registren a la página, en este caso los emprendedores de pequeñas o medianas empresas, se les brindará el taller virtual "Igualdad oportunidades" de forma gratuita.

Objetivo del taller virtual. Aprender sobre los conceptos y temas que rodean la igualdad de oportunidades y los cambios positivos dentro del rendimiento de una empresa al incorporar prácticas de inclusión, igualdad y equidad.

Contenido del taller. Estará compuesto por 4 módulos, Cada módulo abordará un tema que ayude en la comprensión del tema principal del taller. Para el 1er, 2do y 3er, módulo se utilizarán materiales audiovisuales que preparan a los especialistas para desarrollar los conceptos y subtemas. En del 3er módulo se incluirán dinámicas que ayuden a experimentar la visión de igualdad de oportunidades y finalmente el 4to módulo como cierre, se compartirá un poco sobre la historia Laborall.org, y cuáles son los propósitos de la marca a largo plazo de la mano de los aliados, quienes serán en este caso las empresas en proceso de crecimiento. Los temas, subtemas y actividades que se desarrollaran en cada módulo están divididos de la siguiente forma: 


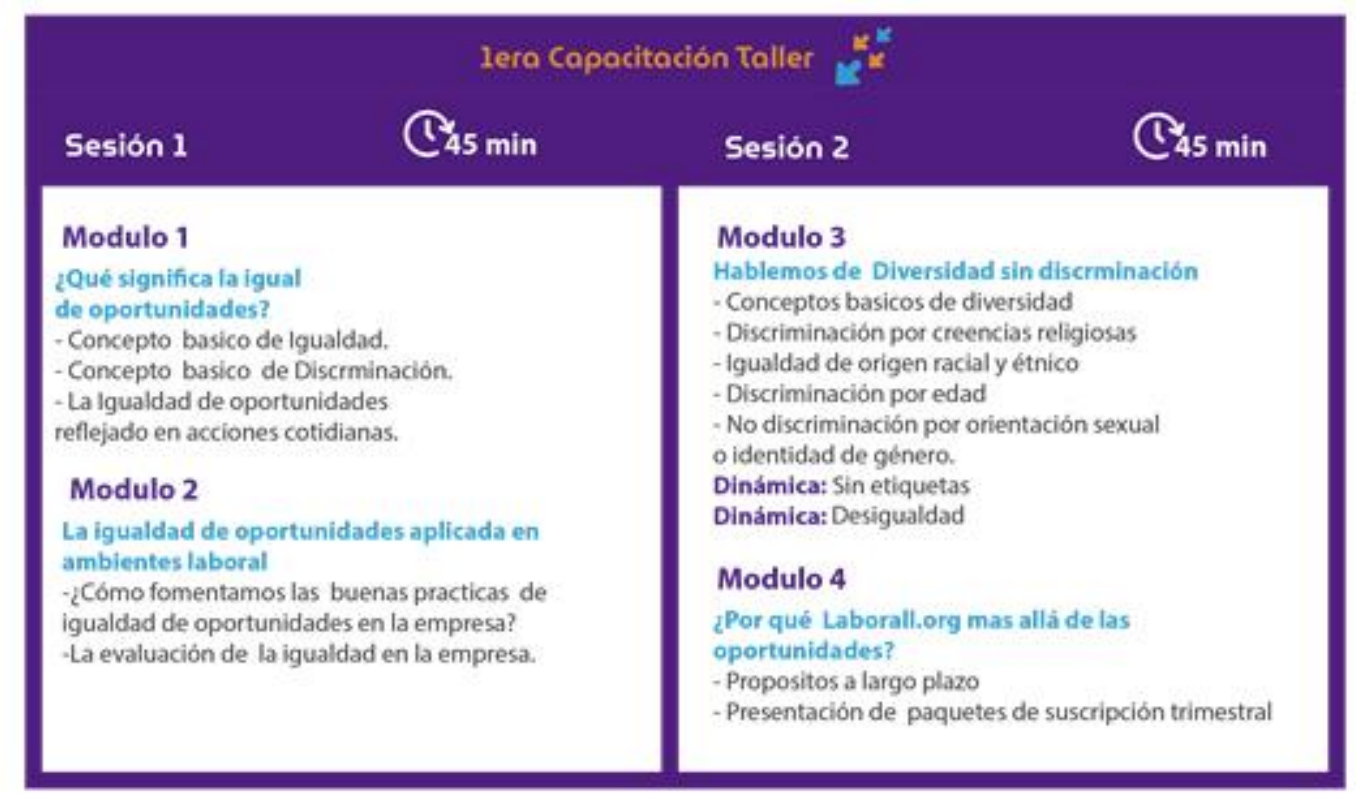

Figura 11. Taller "Igualdad de oportunidades". Fuente propia

Después de dictar este taller gratuito, se les entregará un certificado virtual por haber asistido a las dos sesiones del taller y como reconocimiento extra, se le sumará una estrella en el perfil que crearán en la red social, la cantidad de estrellas que vayan sumando significa el interés y compromiso que tiene la empresa para con sus colaboradores, estas estrellas se irán sumando mientras vayan finalizando talleres o diversas capacitaciones con Laborall.org.

Para finalizar se explicará a los participantes sobre el paquete de suscripción trimestral que se ofrece en laboral.org estos paquetes se dividen en dos categorías, Regular y Premium.

Contenido del Paquete Regular. Selección de personal de 2 a 3 personas, asesorías para evaluar temas particulares de la empresa, ejemplo: Nivel de satisfacción de los colaboradores en la empresa, rendimiento laboral del personal, capacitar al personal con el tema de diversidad, se puede asignar un psicólogo organizacional que lleve a cabo el proceso de selección de la empresa, con criterios de equidad, igualdad. Acceso libre y gratuito a 4 talleres que se brinden en el año. 
Contenido del Paquete Premium. Diseño de campañas internas con temática específica, elaboración de piezas gráficas en publicidad nativas dentro de los espacios de Laboralll.org y menciones en diferentes talleres libres que se den a la audiencia. Acceso libre y gratuito a dos talleres que se programen en la red social cada mes en el año, asesorías para evaluar temas particulares de la empresa, ejemplo: Nivel de satisfacción de los colaboradores en la empresa, rendimiento laboral del personal, capacitar al personal con el tema de diversidad, se puede asignar un psicólogo organizacional que lleve a cabo el proceso de selección de la empresa, generar trivias con criterios de equidad, igualdad.

Con respecto a los usuarios interesados de encontrar oportunidades laborales, también se les brindará un seguimiento inicial, con una charla gratuita sobre esta nueva visión de empleabilidad y una breve introducción sobre los beneficios de laboral, como artículos, la bolsa laboral y talleres que tendrán en muchas ocasiones una tarifa accesible y en casos especiales accediendo algunos participantes a becas o medias becas llenando un formulario.Laborall.org cuenta con un número en el que se podrán hacer denuncias o reclamos con la finalidad de comunicar si sucede un episodio de discriminación o una situación que atente en contra de la dignidad y bienestar del postulante en el proceso de selección o estando dentro de una empresa afiliada. 


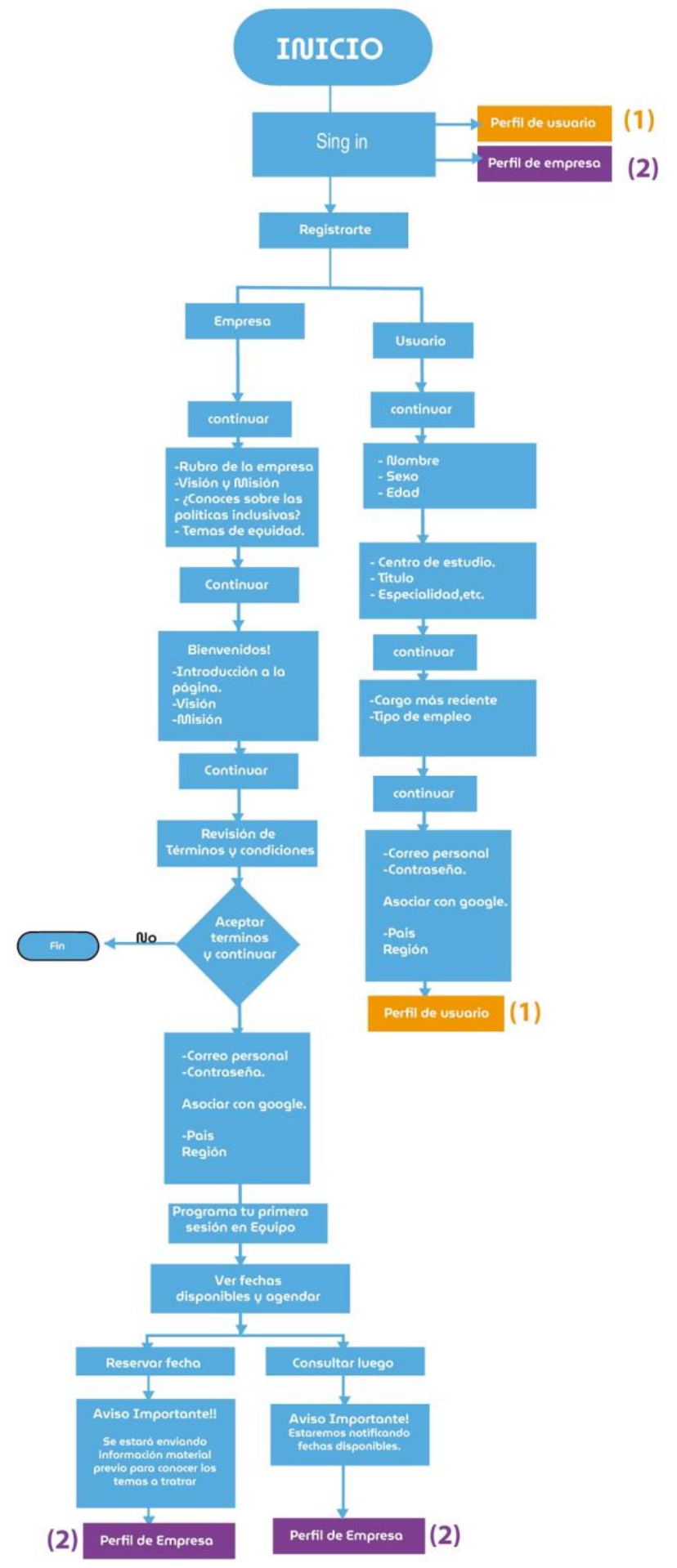

Figura 12. Diagrama de navegación de la red social Laborall.org 1. Fuente propia 


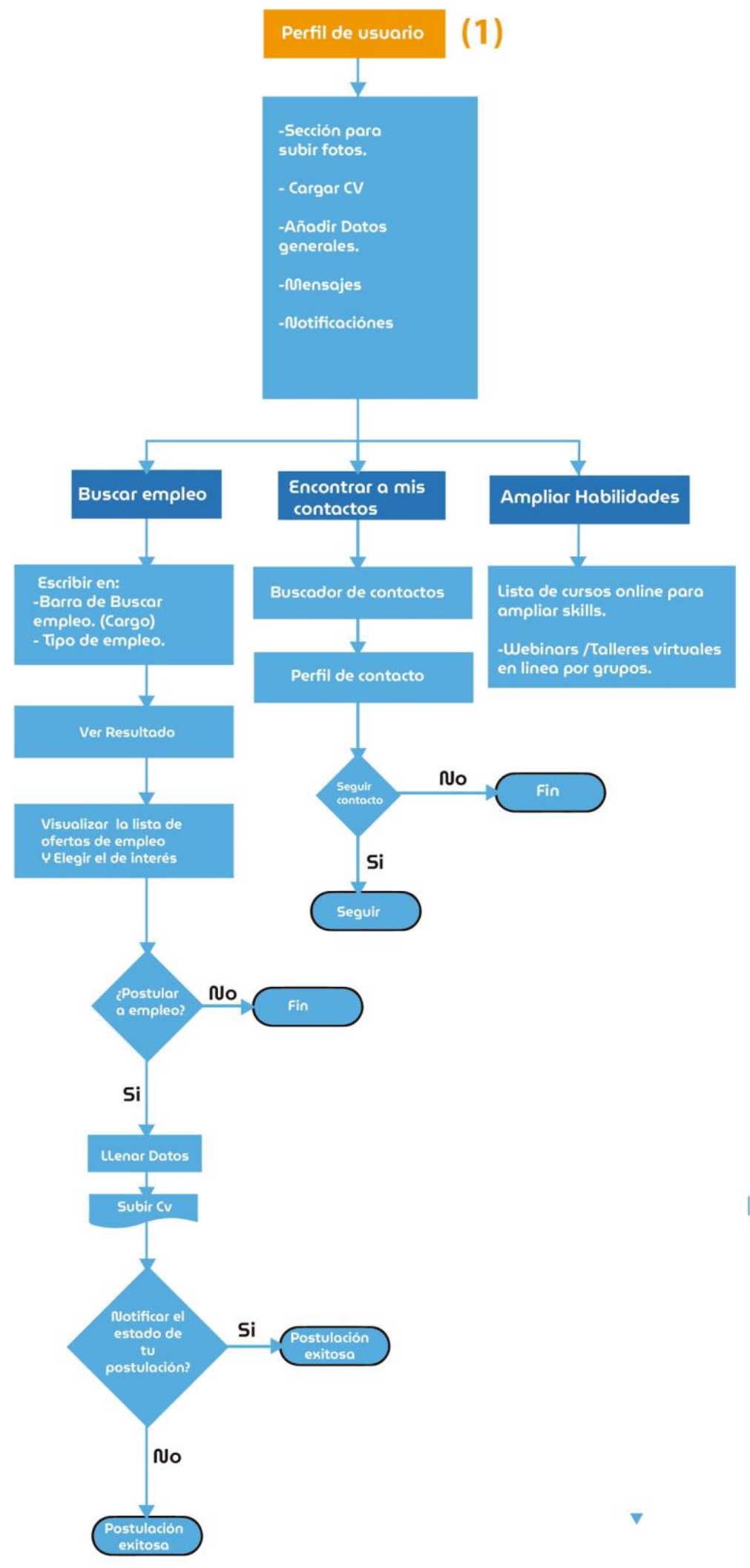

Figura 13. Diagrama de navegación de la red social Laborall.org 2. Fuente propia 


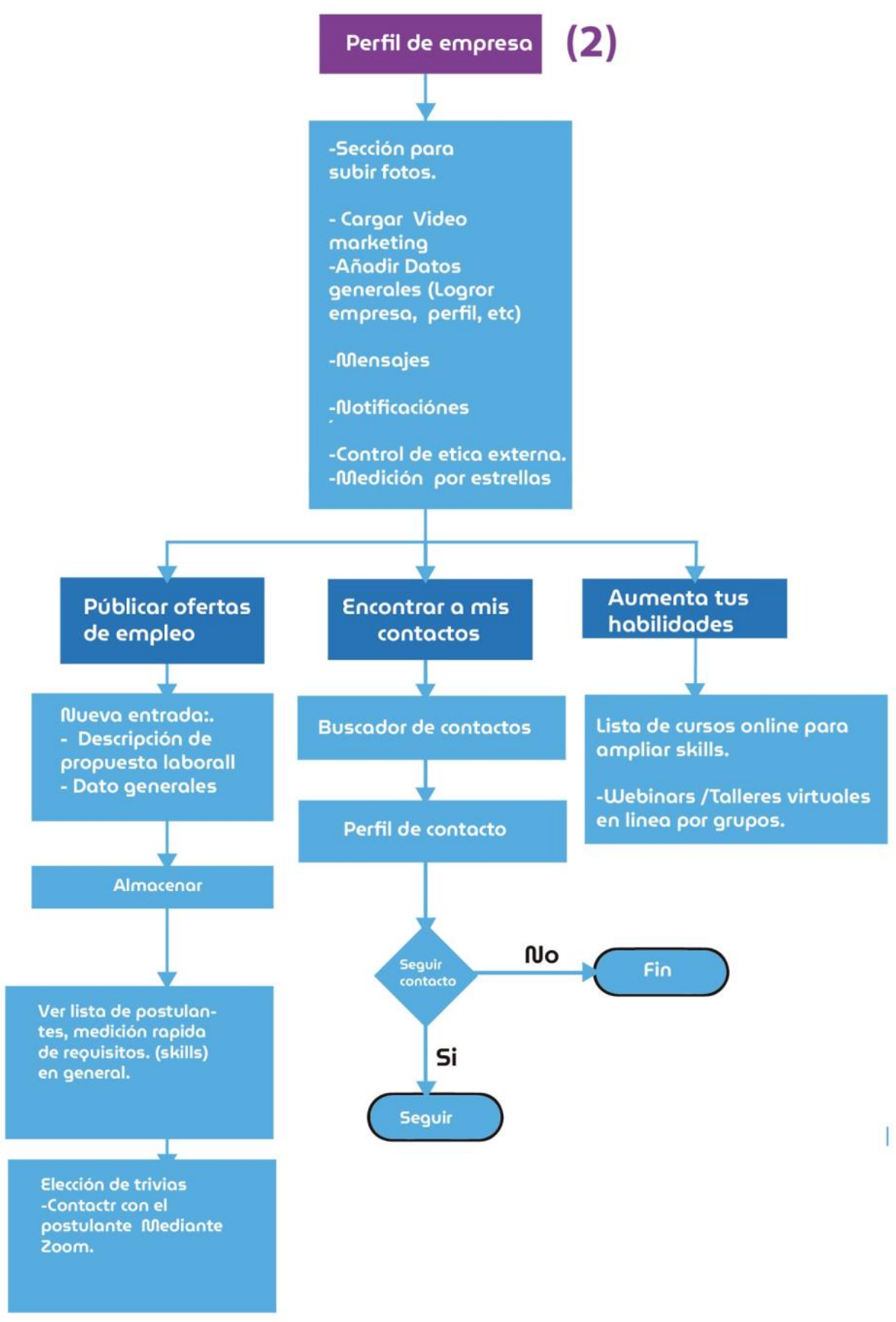

Figura 14. Diagrama de navegación de la red social Laborall.org 3. Fuente propia 


\section{Labớrall.org}

iBienvenidos a Laborall.org un nuevo concepto sobre empleabilidad, en donde los derechos de todos son los más importantes y van de la mano con el respeto, la igualdad y la tolerancia.

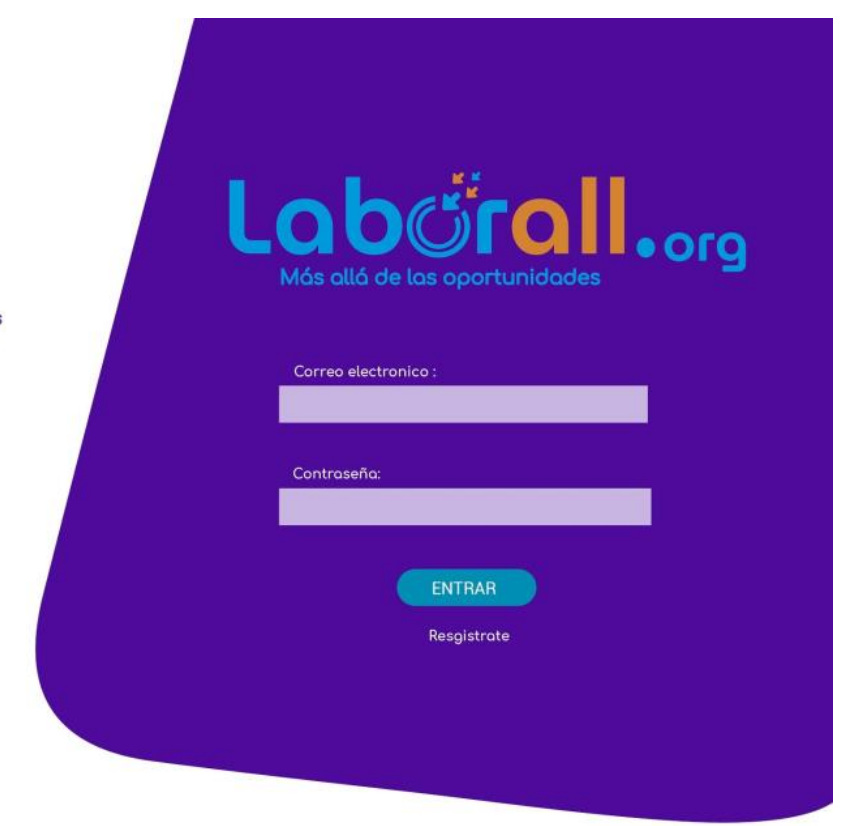

Figura 15. Página inicial de Laborall.org. Fuente propia

\section{Labörall.org}

¡Estamos felices de empezar a concerte!

Figura 16. Registro de nueva empresa 1. Fuente propia 


\section{Labörall.org}

\section{¡Estamos felices de empezar a concerte!}
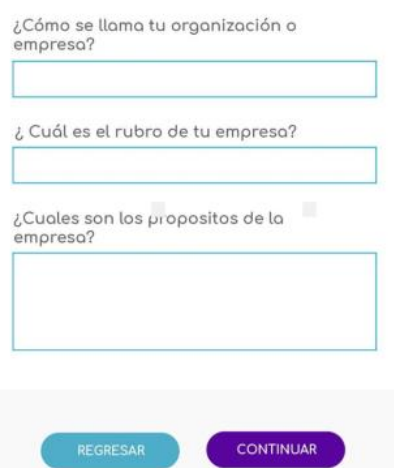

Figura 17. Registro de nueva empresa 2. Fuente propia

\section{Labörall.org}

¡Estamos felices de empezar a concerte!

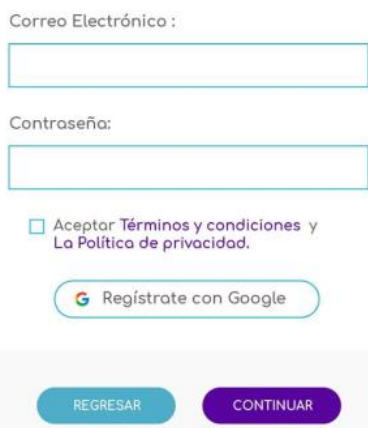

Figura 18. Registro de nueva empresa 3. Fuente propia 


\section{Labörall.org}

¡Bienvenido nlikufrut! hemos preparado tu primera capacitación .
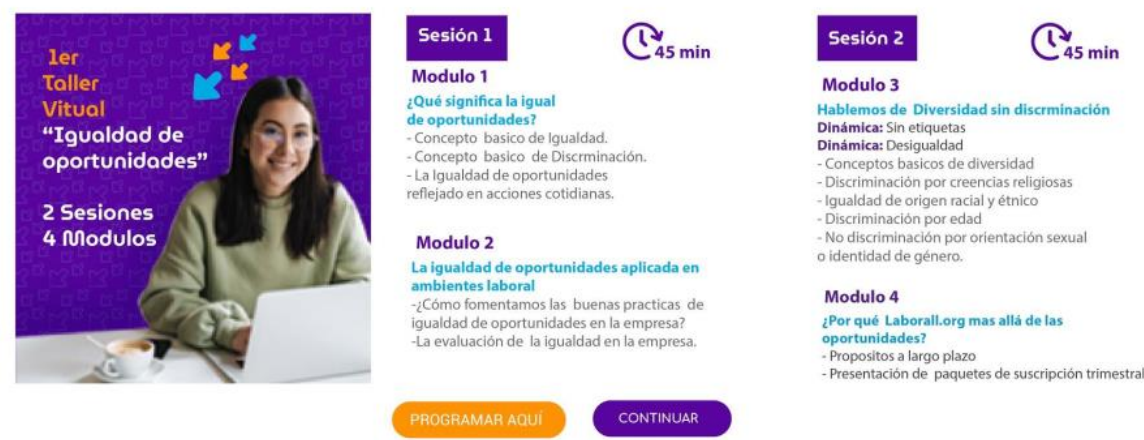

Figura 18. Taller virtual "Igualdad de oportunidades". Fuente propia

\section{Labörall.org}

¡Bienvenido nlikufrut! hemos preparado tu primera capacitación .
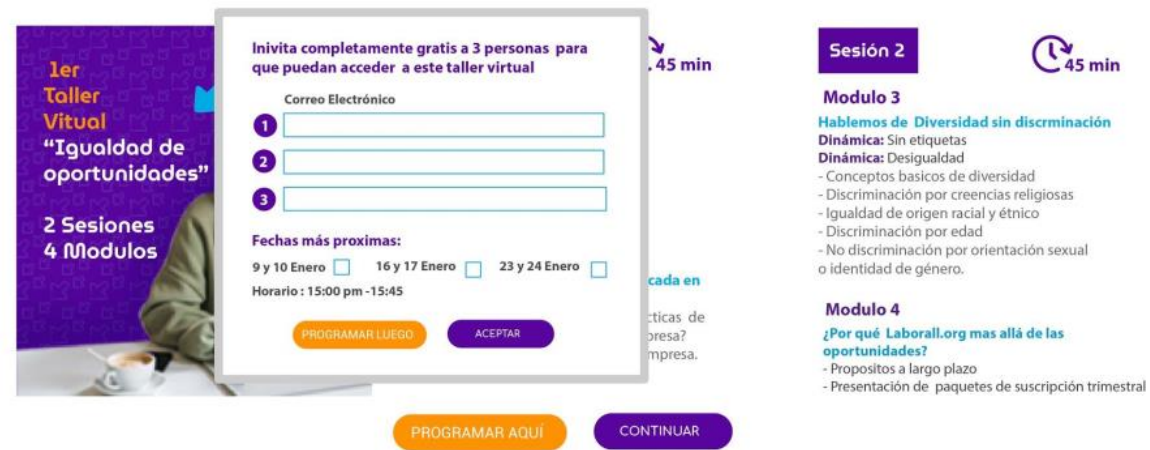

Figura 19. Taller virtual "Igualdad de oportunidades"2. Fuente propia 


\section{Labörall.org}

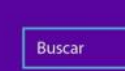

$\sum_{\substack{\text { Bolsa } \\ \text { Laboral }}}^{\infty}$

$\underset{\text { Ampliar }}{\text { an }}$

$\underset{\substack{\text { ariculos } \\ \text { de inters }}}{\equiv}$

peaff
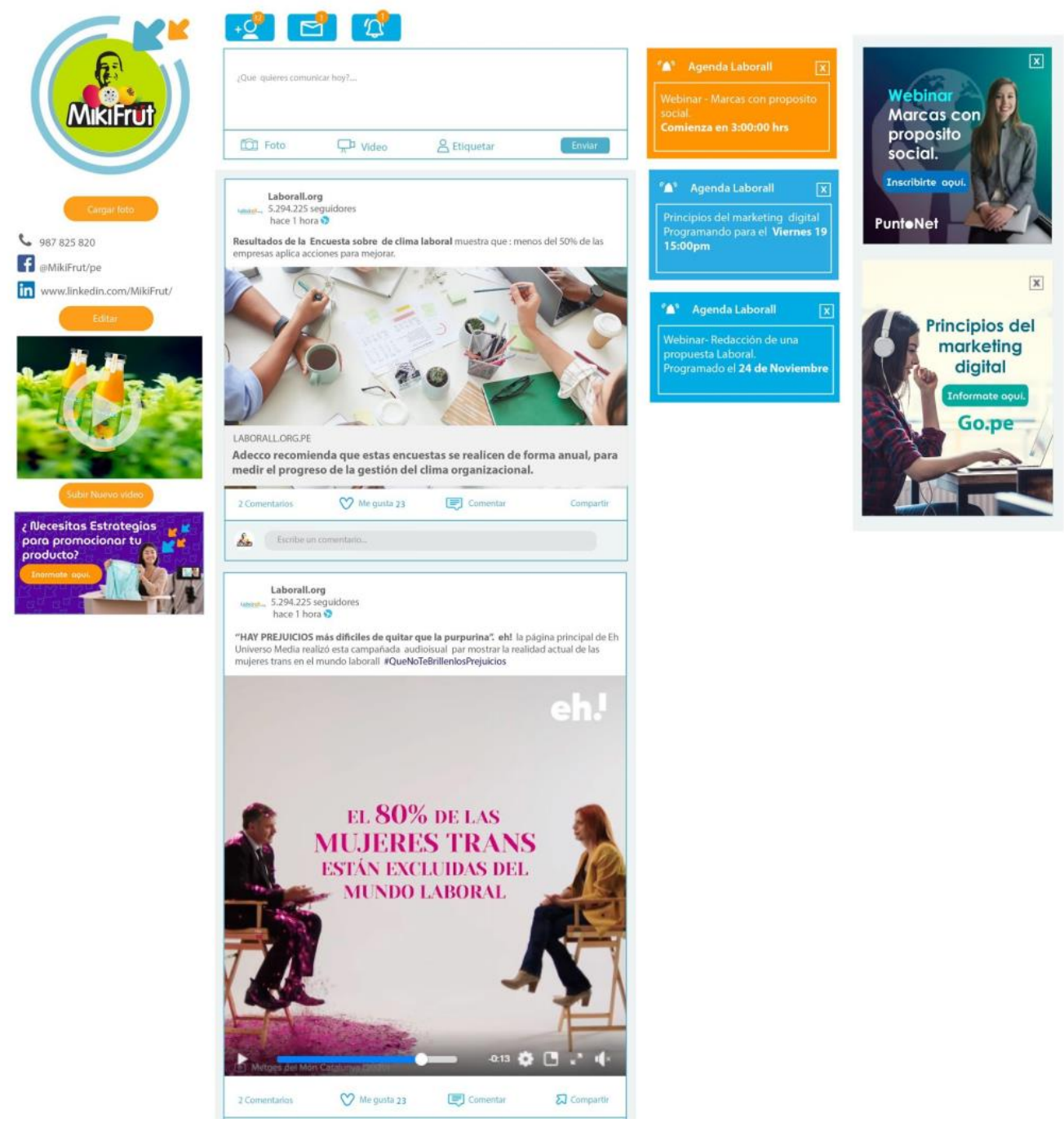

Figura 20. Menú de Empresa en Laborall.org. Fuente propia 


\section{Labơ̈rall.org}

$\stackrel{2}{2}$

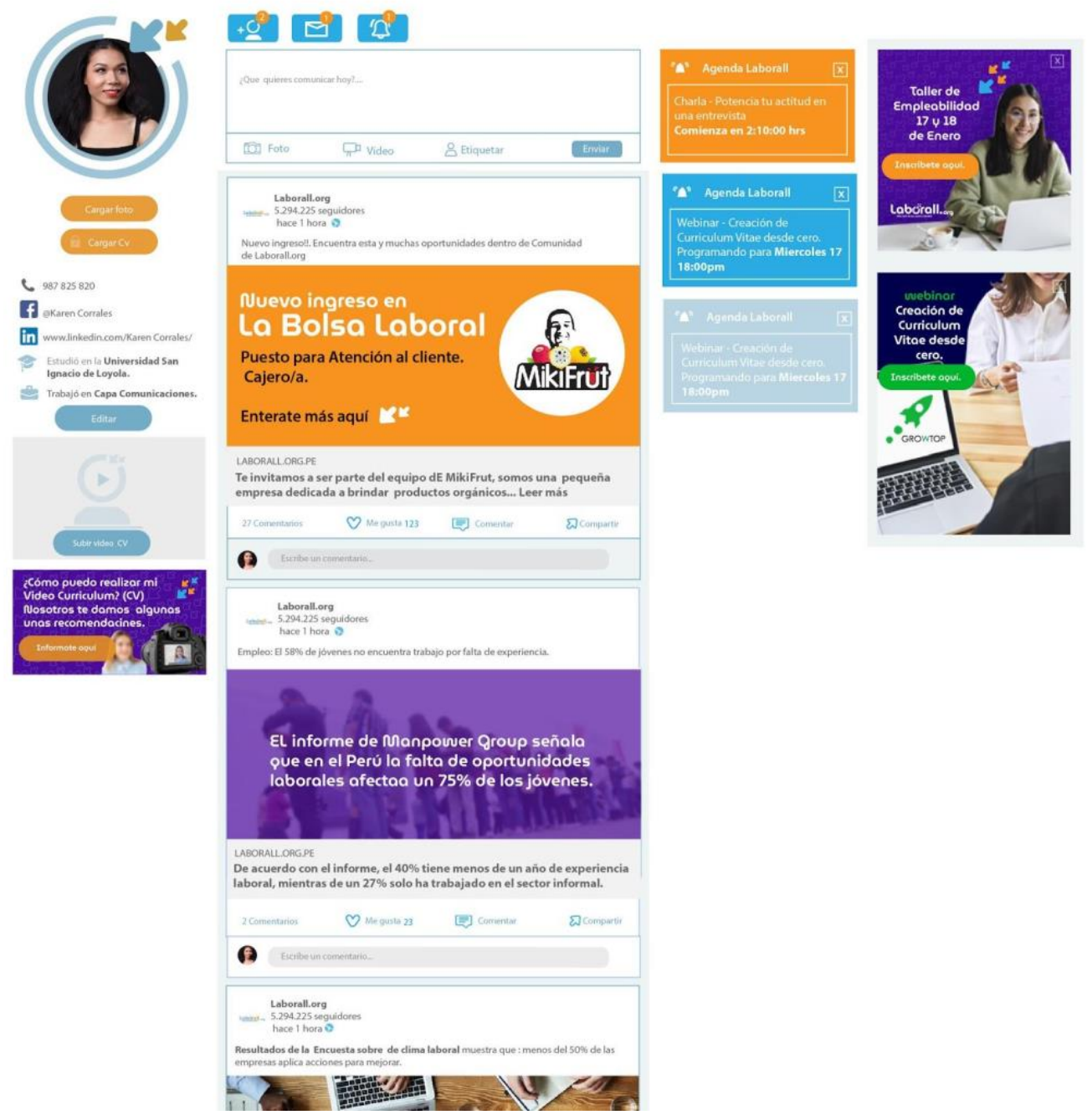

Figura 21. Menú de Usuario (Postulante) en Laborall.org. Fuente propia 


\section{Labơ̈rall.org}

$$
\text { Buscar }
$$

Bolsa

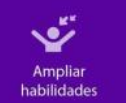

$\underset{\substack{\text { Artcilos de } \\ \text { interes }}}{E}$

Perfil
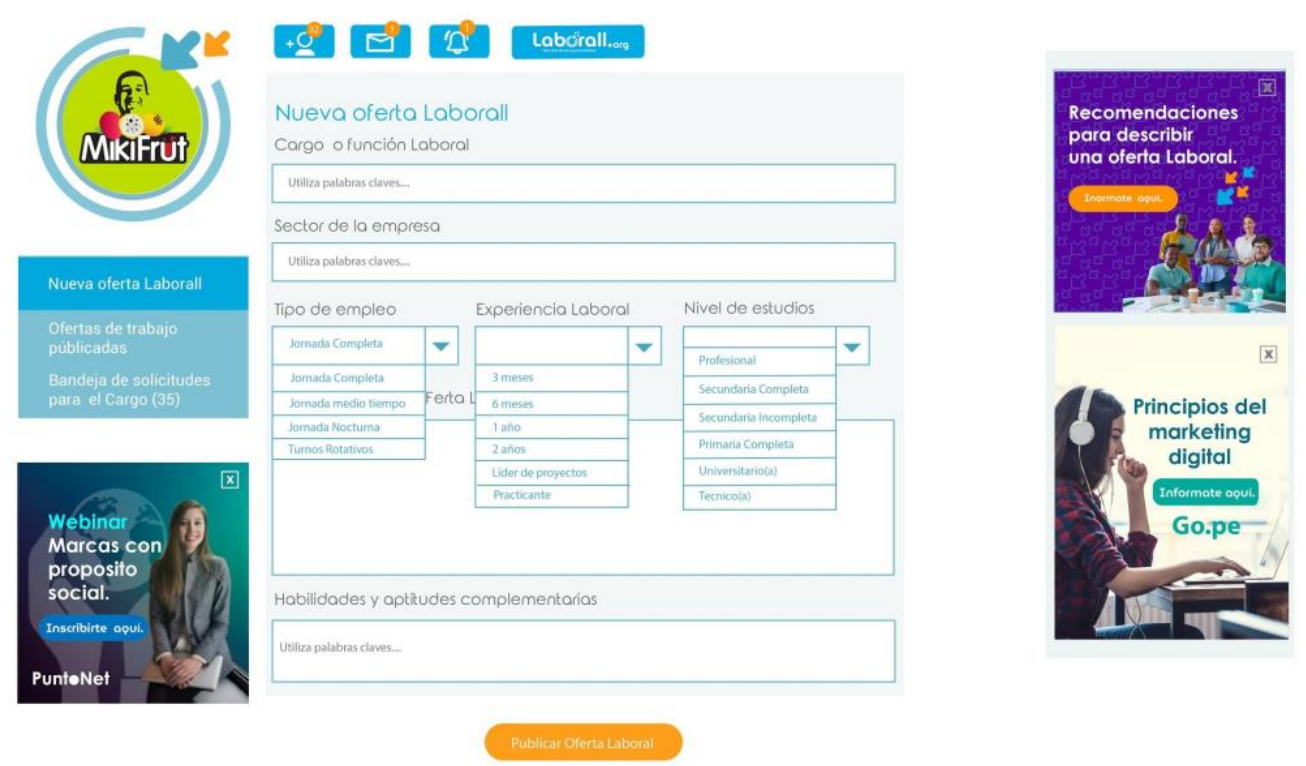

Figura 22. Sección de Bolsa Laboral por parte de las empresas. Fuente propia

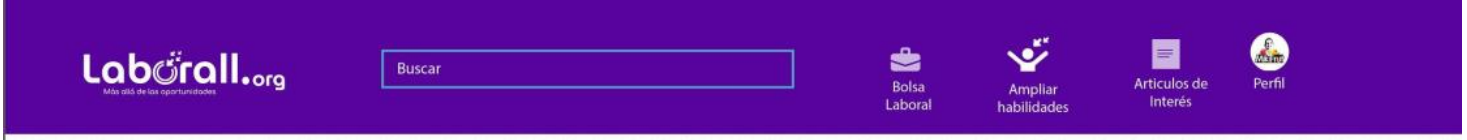

Encuentra Cursos Cortos, Webinar, talleres y mucha información sobre el mundo laboral.
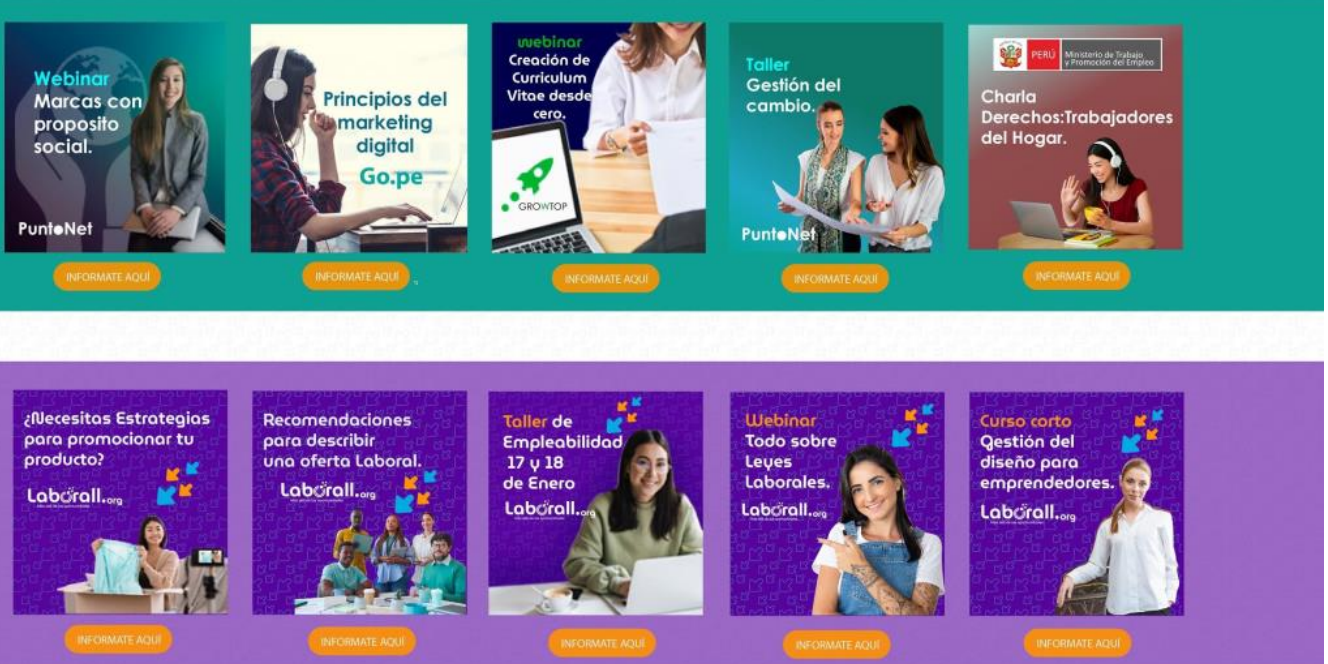
Figura 23. Sección “Ampliando Habilidades”. Fuente propia

\section{Relación entre problema, público objetivo y proyecto}

Debido a la limitada oportunidad laboral que sufren las mujeres trans por la falta de normativas, estigmas y prejuicios que las rodean, surge la necesidad de crear espacios seguros e inclusivos que puedan apoyar en la ampliación de ofertas laborales para esta población, por esta razón los nuevos emprendedores de 28 a 45 años, de medianas y pequeñas empresas son los más próximos a generar nuevas oportunidades laborales, estos líderes emprendedores están en búsqueda de nuevo personal y definiendo sus valores como empresa, por ello se opta por crear una red social laboral que logre bajo las asesorías y talleres, el entendimiento de esta nueva visión de empleabilidad, que los ayude a ofrecer mayores oportunidades laborales con criterios más equitativos y de igualdad de oportunidades.

\section{Marca del proyecto}

El nombre de la marca se compone de la unión de dos palabras, la primera laboral y la segunda "all” que traducido al español significa todos, cuando se junta las dos palabras forman "Laborall.org" para connotar que en esta red social todos los usuarios tienen la posibilidad de encontrar oportunidades de empleo y que al mismo tiempo funciona esta red como punto de encuentro entre empleadores y empleados. Se añade además las siglas Org debido que detrás de esta red social se encontrará toda la organización trabajando en el mantenimiento, monitoreo capacitación, afiliación y certificación de las empresas y usuarios que cada vez irán sumándose a esta red de oportunidad laborales. 


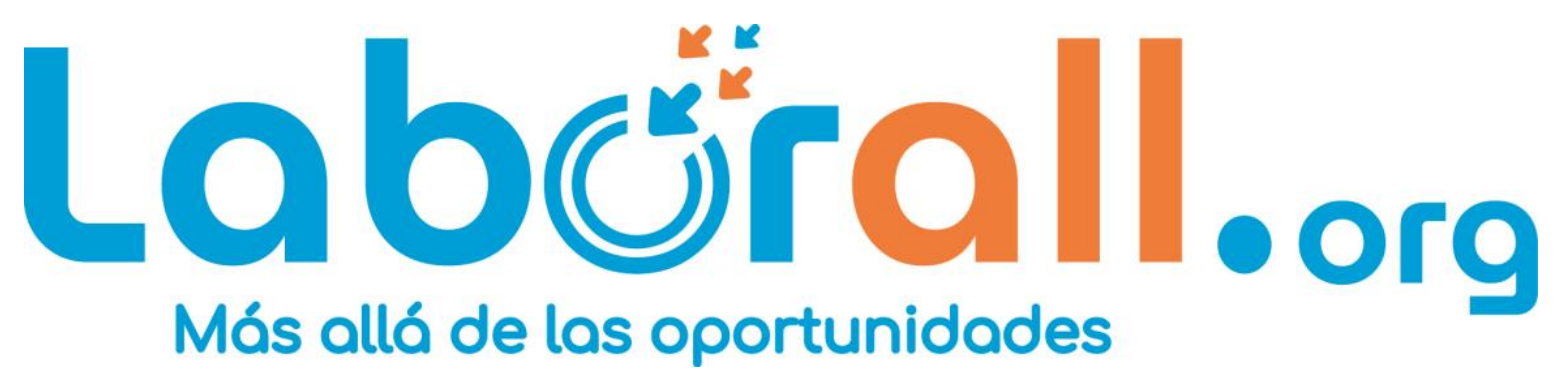

Figura 24. Logotipo de la marca Laboral.org. Fuente propia

\section{Reflexiones}

La relación entre el proyecto y la evaluación de juicio de pares, es la idea de seguir mejorando la plataforma, añadiendo nuevas herramientas que ayuden a crear una cartera de oportunidad laboral amplia, algunos especialistas concuerdan que es necesario crear estos espacios que generen mayor inclusión y oportunidades que ayuden visibilizar poblaciones vulnerables y que por muchos años han sido víctimas de rechazo, discriminación por desconocimiento y falta de capacitación al entorno que rodea a estas personas. Se comenta además que se presente el proyecto como un startup que ayude a generar cambios sociales y ayude a promover puestos laborales a la población trans.

\section{Conclusiones}

Según lo que indican las encuestas realizadas a nuevos emprendedores de medianas o pequeñas empresas de 24 a 45+ años de edad, más del 40\%de ellos no tienen conocimiento sobre las políticas inclusivas y lo que contienen o implica establecer estas normativas en la organización que lideran.

Con respecto al proyecto, se pretende replicar esta propuesta de red social para lograr un mayor alcance con el propósito de ampliar la red de empleados y empleadores, aportando 
además a que más personas y empresas se sumen al cambio, al desarrollo personal y profesional de todos sin distinción.

La red social "Laborall" también se proyecta a aumentar espacios virtuales que ayuden a fomentar el financiamiento de emprendimientos creativos y de carácter sostenible para apoyar a poblaciones que necesiten de beneficios laborales económicos, según el contexto actual en el que se encuentren.

La carencia de oportunidades laborales en mujeres trans del Perú no solo compete o involucra al estado que es el principal encargado de velar por el bienestar de su población, sino también de la sociedad que tiene la posibilidad de generar oportunidades para esta comunidad en diferentes niveles o ámbitos, como en lo laboral, sin embargo se observa que un cambio va de la mano con la educación y capacitación que ayude a entender porque se necesita normativas que protejan a esta comunidad y que ayude a vencer estigmas y prejuicios que obstaculizan el desarrollo normal y como ciudadana de una mujer trans. 
Anexos

Anexo 1. Violencia sistemática de las Autoridades contra mujeres trans trabajadoras sexuales en Lima

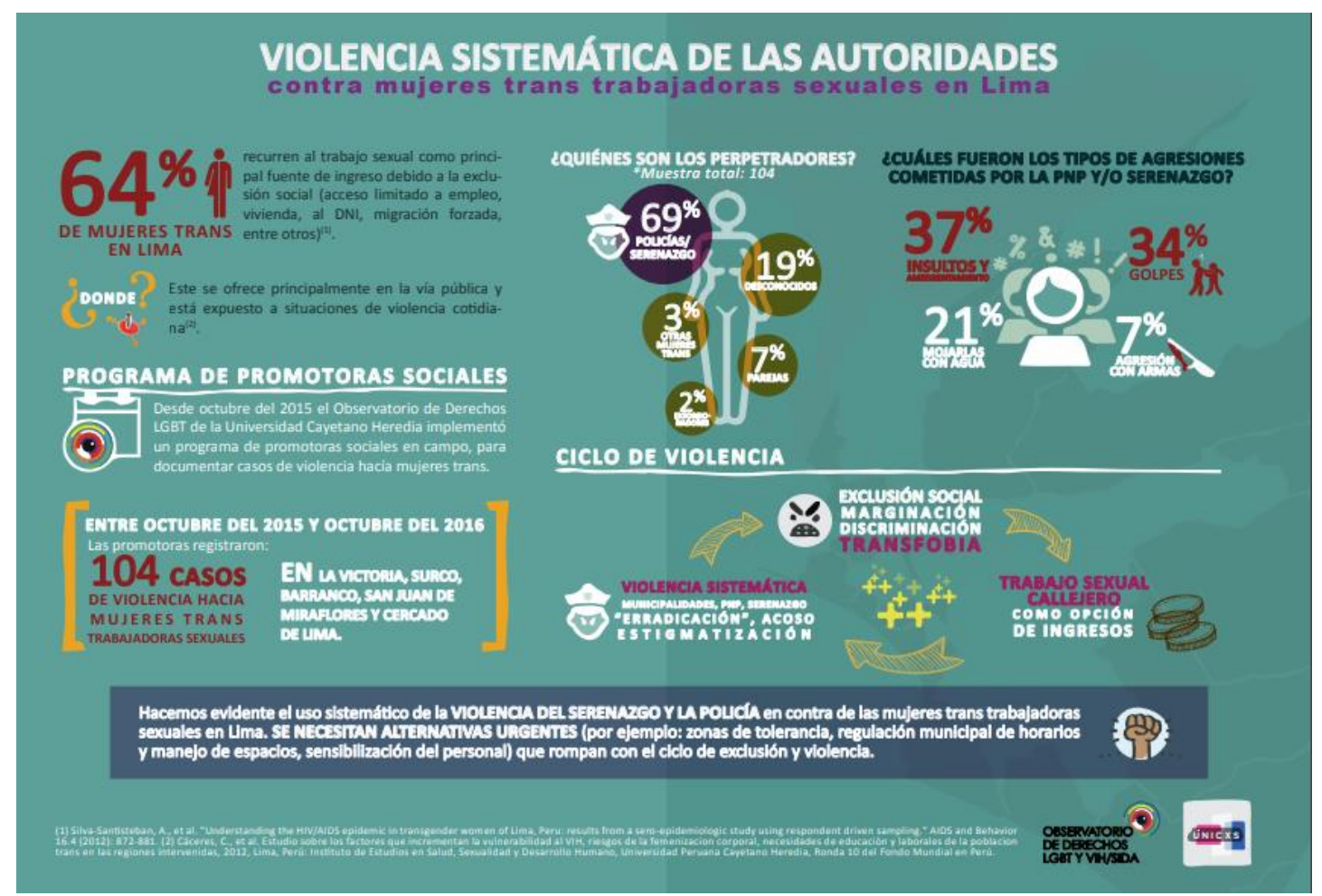

Anexo 2. Entrevista a Leyla Huertas - Líder del colectivo Féminas Perú

Motivo de la entrevista: Conocer cuáles han sido sus logros, obstáculos y alianzas que han

Obtenido a lo largo del tiempo como colectivo y saber las necesidades

De la comunidad.

En el Perú, ¿Está presente la discriminación trans?

Si, y está validada, el hecho de que no exista un reconocimiento de nosotras como personas, que la identidad de género no esté dentro de la constitución política, te hace ver una diferenciación en el trato, porque no existes para el estado, partiendo de ahí empieza o comienza el trato diferenciado de las personas. 


\section{¿Cómo limita laboralmente ser una mujer trans en el Perú?}

El hecho de que tus nombres con los que te idénticas no coincidan con los nombres que aparecen en tu DNI, o tu imagen, expresión de género no conocida con el nombre de tu documento de identidad, hace que se te cierren las puertas, validen y legalicen la discriminación, lo hemos podido ver hace `poco en el tema de las restricciones de sexo como utilizan la información del DNI para negarte el libre derecho tránsito, esta es una muestra clara de cómo el estado hace que las personas transexual sea excluida.

\section{¿Qué debe hacer una persona transferente a la discriminación en su centro de trabajo?}

Creemos que no discriminamos, que no somos homofóbicos, machistas, pero tenemos todo ello encima por todo lo que hemos crecido. Primero que esa persona tenga mucha información básica sobre ello, pero lamentablemente se pueda tener mayor acceso hace unos años que recién se habla sobre estos términos de diversidad en identidad de género, no hemos tenido esa formación, además de pedirle a esa persona que quizá no terminó el colegio y si lo termino quizá con episodios de violencia, poder pedirle que explique o cuente como es, es un poco complicado.

Nos comenta que Los estados deben invertir en la educación de las personas para poder hablar sobre un enfoque de género a todos los niveles, de esta manera se puede entender que todas personas se deben respetar por quienes son, sin juzgar en función del sexo con el que se nace, ya que hablar de enfoque de género es hablar sobre personas, ya que somos.

\section{¿Cómo es tomado el colectivo trans en la sociedad?}

Creo que existe un cambio, socialmente La gente va entendiendo la problemática , me parece bien que exista una influencia en la educación sobre el tema, que hayan en universidades privadas más que nacionales este interés de hablar sobre el enfoque de género, tratar y luego 
entenderlo ,porque somos personas y debemos respetarnos, independientemente del sexo con el cada persona nazca, la cultura en la que se desarrolla, la etnia en el que pertenece, el género habla sobre el respeto de las personas, en ser diversos, podemos ser diversos hasta en lo que creímos que era estático como era el sexo, hasta en eso somos diversos y debemos respetarnos, creo q todo está cambiando poco a poco pero lamentablemente creo que las personas que están en puestos de poder y pueden cambiar más las cosas, el problema es más legal que social, lamentablemente si está ligado, pero el gran impedimento es lo legal no?, todos estos grupos conservadores que crean leyes para su conveniencia.

\section{¿De qué manera está organizado el movimiento colectivo?}

Se ha ido formando y organizando, en función de nuestras necesidades, é dado mucho tiempo para que sea un proceso comunitario, y no salga de mí misma cómo debe funcionar desde el inicio..., eso quizá ha hecho que sea que sea más lento el desarrollo, pero creo que, todo tiene un tiempo de maduración, creo que hemos pasado por ese periodo, seguimos planteando estrategias y consiguiendo cosas, seguimos formándonos, no puedo decir que estamos organizadas completamente con un organigrama planteada, creo mucho en que todas debemos participar en ello.

\section{¿Qué obstáculos se han presentado a lo largo de este tiempo en el colectivo?}

Lo principal....el tema de los trolls es un tema súper fuerte lamentablemente en el periodo en el que empezamos a existir, también empezó a existir lo de mis hijos no te metas y todas estas baterías de herramientas que estos grupos utilizaron o siguen utilizando para poder callar las voces de las personas ,como por ejemplo las redes sociales han sido los trolls, más aun teniendo en el congreso gente de este tipo y en paralelo gente que se dedicaba hacer eso en redes, hemos tenido un ataque fuerte, hasta ahora lo vivimos y lo sufrimos pero no con la misma intensidad que vivimos con el anterior congreso. 
Si hablamos de impedimentos legales, pues son los grupos de poder conservadores que entorpecen leyes, los que hacen que las cosas no sean como deberían de ser, y te ponen justificaciones realmente tontas para, por ejemplo: tener dentro de las casillas por ejemplo que eres una persona trans.

Serían los trolls y estas personas de poder que tienen puestos importantes que impiden que políticas públicas que nos miran a nosotras, realmente se ejecuten, se escriban o realmente se hagan.

\section{¿Cuáles son sus canales de difusión?}

Tenemos Instagram, Facebook, YouTube y no lo usamos mucho.

\section{¿En un futuro, considera una solución frente a esta problemática?}

Una ley de identidad de género aliviaría o comenzaría a aliviar el problema porque reconoces de un grupo de personas, pero la solución es integral y conjunta tiene que ser por muchos ámbitos... Empecemos por la ley de identidad de género de la persona esto sería un paso importante.

\section{¿Qué logros y alianzas han conseguido a lo largo de este tiempo como colectivo en el ámbito de derechos humanos y/o laborales?}

1ero fue en el 2015 estar entre el plan nacional de violencia contra la mujer, 2016 - 2021 que habla de las mujeres, en el marco teórico, y menciona que este este plan está ejecutado pensando en las mujeres y en su diversidad, menciona de mujeres trans, mujeres afro, mujeres con discapacidad.

2do La norma técnica para mujeres trans 2016 fue escrita y aprobada en el 2016. 
En el 2017 se consiguió un convenio con el ministerio de trabajo, con el programa de Perú responsable de trabajo inclusivo, para mujeres trans, en la cual se logró el convenio, luego el programa se cerró, pero se consiguió que una chica entrara a la empresa Bakery.

Seguimiento de los juicios de cambio de nombre para las mujeres transexuales con vías más cortas desde el 2015.

1er Censo Trans virtual 2019...En el 1er censo virtual que se realizó en el 2019.... Con la participación de 700 mujeres trans...dio como resultado con respecto al tema del trabajo, que un $42 \%$ de mujeres transexuales se dedica al trabajo sexual, un $31 \%$ en trabajos informales y un $27 \%$ no trabaja, es posible que sea más alto de lo que a simple vista parece ya que algunas mujeres Trans no ven la prostitución como un trabajo.

\section{Anexo 3. Entrevista a Diego Pebe - Psicólogo Organizacional}

Motivo de la entrevista: Conocer una perspectiva desde el lado empresarial sobre la inserción laboral de mujeres trans. 


\section{A nivel empresarial ¿cómo se están aplicando las políticas de inclusión?}

\section{¿Como por ejemplo la comunidad LGBTIQ+ en las organizaciones?}

La realidad de las empresas a nivel Perú, de hecho, estas políticas se están ampliando más debido a lo que he podido conocer hay una organización que conecta a empresas grandes y participan en estos lineamientos de inclusión. Una de las principales que yo conozco Es IBM una organización que ayuda, aporta, capacita y sensibiliza a muchas empresas con respecto a los derechos e inclusión de la minoría LGBTIQ+-

\section{¿Cómo se aplica?}

Primero es la sensibilización, hacen capacitaciones a los mismos colaboradores de las empresas, para que respeten y para que aprendan a convivir con esta diversidad que se vive actualmente en nuestro país, tener esa conciencia del respeto, que es importante en el ambiente laboral y el clima organizacional también.

Otra cosa que hacen es la visibilización de las personas y ayudarlas hasta con seguros de salud.

Como Interbank que da esa opción que es asegurar no solo a tu familia sino si tú tienes una pareja del mismo sexo o del género con el que te idénticas. Estas empresas que forman parte de este movimiento, que fomentan la diversidad como Scotiabank por ejemplo, incluyen estas políticas de anti discriminación dentro de sus reglamento internos de trabajo pasando estos como faltas graves, entonces esto significa que los trabajadores pueden sentirse seguros de quienes son, sin sentir temor de ser expuestos ante este tipo de discriminación y si es que pasaran por alguna experiencia de discriminación dentro del trabajo, el reglamente interno de trabajo es suficientemente estricto para sancionar a las personas en que esto es verdaderamente una falta grave e inclusive en algunos casos, causal de despido, porque en las 
leyes peruanas si cometes una falta grave que esta puesto en el reglamento interno de tu trabajo puede existir una desvinculación.

\section{¿Qué sucede con las empresas o quizá Mypes que no aplican estas políticas de inclusión, en este tipo de empresas existe la discriminación?}

No te podría dar una data exacta, pero que creo que esto parte por la educación o quizá parte por esta sensibilidad interpersonal que a veces no se da con los demás, cosa que tiene que ver con la parte de los principios y los valores que aprendes en casa.......considero que se puede dar por un tema de desconocimiento, pues lo que no se conoce, lo que no se estudia o investiga, posiblemente se puede crear un rechazo o una reacción diferente, diferente para uno mismo pero no pasa los demás, posiblemente en las pequeñas empresas en Mypes se genere discriminación quizá no por un tema de mala fe sino un tema de desconocimiento y poca visibilidad, sería bueno saber cuánta visibilidad tiene la empresa y saber cuál es su opinión sobre el tema y como se sentirían contratando a un persona de la comunidad LGBT, tomando en contraste la medición del rendimiento de trabajo y viendo si esta persona postulante cuanto puede congeniar con el puesto de trabajo.

\section{¿Qué obstáculos puede presentar la empresa para contratar a una mujer trans?}

En el Perú no es pública o legal hacer el cambio de identidad porque la constitución lo ampara...No ampara ese cambio, puede ser un reto o un desafío para la empresa contratar a una persona transexual sin embargo no es imposible, se sabe que en los papeles legales como: En una contratación, boleta de sueldo, planilla, fotocheck debe ir puesto los nombres que sale en el Documento de Identidad Nacional, porque todo eso es legal y no se puede ir en contra de la ley del Perú...... Entonces esta persona quiere un trato justo y la empresa también quiere dárselo pero la ley por ese lado no ayuda.......Esto puede generar en la persona una frustración humillación en forma significativa, sin embargo a pesar que pueda ser un 
obstáculo o desafío aún es posible tomar este talento y hacerlo parte de la empresa, apoyándolos por el lado de ponerles en su fotocheck el nombre con el que se identifica y el momento en el momento en el que se identifique con sus compañeros lo haga con el género con el que se identifica.

\section{¿Puede darse el caso de discriminación por parte de los compañeros de trabajo?}

Creo que sí, se puede dar un tipo de discriminación por más que las empresas tengan políticas de inclusión ya que por ejemplo el tema del baño que sabemos existe para hombre y para mujeres, y luego puedes ser una persona transexual y piensas: yo me idéntico con un género, pero ahora ¿a qué baño voy?, se crean dudas también entre los compañeros, este tema está mucho en discusión, en este tema debe haber políticas que respalden... la ONU debe ver cómo debemos manejarlo en el Perú, debido a que en el Perú recién está comenzando este conocimiento por la diversidad y la inclusión laboral de la comunidad LGBTIQ, pero se está intentando, al fin de cuentas parte mucho sobre las reglas de juego de una empresa, como lo maneja de manera interna.....se deben tomar medidas para que la persona no se sienta afectada y baje su productividad debido a que se puede originar un mal clima organizacional y se generan renuncias, la idea de que se baje la productividad por la discriminación no tiene coherencia.

\section{¿Qué problemas emocionales causa la discriminación dentro de un ámbito laboral las personas trans?}

Menciona que Pueden sufrir de trastornos psicológicos como ansiedad, frustración, borderline debido a la demanda del jefe o de los compañeros, sería bueno que SUNAFIL deba fiscalizar en cuanto a la seguridad y salud ocupacional dentro del trabajo.

\section{¿Qué acciones por parte de la persona puede optar frente a un caso de discriminación por género?}


...Lo primero que hace esta persona es levantar una alarma de violencia o discriminación a través de un canal de ética por un correo o llamada, también puede hacerlo hacia otra empresa que este fuera de la empresa que vea el tema de abuso sexual, etc.

Luego se pasa por una investigación, durante esta investigación se le da el apoyo correspondiente a esta persona, se recoge su testimonio, se recoge por qué y se le da protección durante el tiempo de investigación, para ver si existe indicios de que estas conductas fueron evidenciadas dentro del trabajo.

En el caso de que sea así la sanción depende de qué categoría la empresa cataloga esta falta, usualmente el tema de discriminación es grabe y lo que se intenta no es despedir a esta persona que cometió la falta sino trabajar con ella para sensibilizarlo y hacerle ver que cometió un error quizá por un tema de desconocimiento , pero a la vez ponerlo en alarma a través de una sanción económica o de suspensión ;Sin embargo, si no se ve una mejora o ves el mismo incidente con la misma persona, se puede optar por la desvinculación.

\section{¿En las empresas se toma en cuenta al consumidor para la toma de decisiones con respecto a la selección del personal?}

...Sí, lamentablemente en el Perú se toma en cuenta al cliente final o a los colaboradores que trabajan en el entorno y pueden llegar a ser los compañeros de esta persona transexual ya que si la empresa no está suficiente mente capacitada en el tema y capacita o no sensibiliza a sus colaboradores menos va poder lidiar con esta persona cuando ingrese, porque puede sufrir maltrato y discriminación dentro de la empresa y la empresa puede salir penada por el lado legal.

Las empresas se cuidan y no porque no quieran dar oportunidad a estas personas sino porque no tienen la capacidad instalada para poder decir a sus colaboradores que no le hagan daño sino pues la empresa va pagar los platos rotos. ...por otro lado está el consumidor, la empresa 
toma en cuenta a quien se va atender y ese público objetivo qué tan educado está sobre la diversidad de diferentes minorías, esto ya sería un tema de desconocimiento y riesgo, porque si esta persona se expone bajo un trabajo a un cliente que es agresivo o que genere esta situación de discriminación, es posible que se haga más grande el problema y escale hasta llegar a escalar con la empresa, por eso las empresas podrían tener un prejuicio sobre contratar a personas trans, sobre todo en los puestos de atención al cliente personas de oficinas, bancos....En resumen, es un tema de riesgo, sus políticas, sus colaboradores no sensibilizados y sus clientes que también pueden ser nocivos para alguien de la minoría. Aunque podemos decir que la empresa no está tomando acciones para que esa realidad cambie.

\section{Anexo 4. Entrevista a Diego Borja- Psicólogo Clínico}

Motivo de la entrevista: Trata temas emocionales y de salud mental, gracias a esto tiene un acercamiento con la comunidad LGBTIQ

\section{¿Qué problemas emocionales causa la discriminación en las personas trans?}

Tienen una sensación de poca ayuda, de no encontrarse, sentirse otro dónde no se sienten cuidadas.

\section{¿De qué manera influye la familia en la condición emocional de una persona trans?}

Las personas que tienen apoyo de su familia son muy pocas en realidad en especial las mujeres transexuales, por esta situación de vulnerabilidad y desconocimiento sobre la identidad, terminan siendo echadas de casa y ejerciendo trabajos sexuales.... En contraste las familias que apoyan a las personas trans es súper importante porque existe una especie de contención emocional por parte de la persona y eso les ayuda a no interiorizar esta violencia 
que reciben por parte de la sociedad si no por el contrario enfrentarla. Lo que se ha identificado es que muchas de las personas interiorizan la violencia y concede este permiso de ser violentadas.

\section{¿Cómo se puede solucionar la salud mental de estos trabajadores frente a un caso de discriminación?}

...He notado que ellas cuentan y saben cuáles son sus derechos, las mujeres trans que perecen a organizaciones saben cuáles son sus derechos, ellas lo reconocen, lo que se busque se alienten a denunciarlo, si bien el gobierno como un delito la discriminación por orientación sexual (recién ha salido esto por la pandemia), no da el criterio necesario para que las mujeres transexuales puedan denunciar. Intentan “estar más feminizadas “ para resaltar su feminidad, pero eso la sociedad lo utiliza para violentarlas.

\section{¿Estas personas son aptas anímicamente para rendir en el trabajo?}

No he encontrado algún componente emocional que este en relación el rendimiento laboral en el caso de las mujeres transexuales ya que más del $50 \%$ se dedican a trabajos de subordinación como trabajo sexual o como animadora, todos estos conceptos que se tiene de las mujeres transexuales, no se ha podido encontrar algún componente emocional porque no tienen acceso a una oportunidad laboral.

\section{¿Qué causa emocionalmente a futuro una persona que no puede conseguir trabajo?}

Puede ocasionar, ansiedad, depresión, el problema en este caso es que te puede tomar como 16 años para cambiar tu nombre en el DNI, quien se aproxima a la entrevista no es la persona que aparece en el DNI y no cuenta con los estudios superiores o requerimientos necesarios para acceder al trabajo entonces esta idea de desesperanza y existe una disonancia en el ideal 
de ellas de encontrar un buen trabajo y la realidad sobre las limitadas oportunidades laborales, de ahí ya se marca una desigualdad y no llegar a un ideal de lo que se quisiera.

\section{¿Qué debe hacer una persona trans para evitar sufrir este tipo de daño emocional?}

Creo que debe existir una contención entre familia y amigos para apoyarla y también se creen ella, pero lo más recomendado es que se creen leyes públicas que las ampare, existen estudios donde muestra que las mujeres transexuales están en total vulnerabilidad y por ello no han tenido oportunidad desarrollar una inteligencia emocional, sólo para sobrevivir en muchos casos, no por eso siento que es importante que un grupo de personas le brinde esta contención emocional.

¿Cómo se podría concientizar a las empresas o compañeros sobre la diversidad de identidad?

Todo empieza por la educación, y con la ayuda de organizaciones que fomentan o promueven esta información sobre diversidad de identidad de género y muchos temas sobre respeto, tolerancia y políticas inclusivas.

Anexo 5. Entrevista a Silvana Rosales-Dra. Abogada, especialista en casos de cambio de sexo y nombre en personas trans a nivel legal

Actor: Especialista en casos de cambio de sexo y nombre en personas trans a nivel legal

¿En la actualidad, existen leyes que protegen a las mujeres trans de un episodio de discriminación o transfobia dentro del ámbito laboral o en una entrevista laboral? No tenemos una ley específica respecto a sobre discriminación laboral... pero si bien no existen leyes específicas existe una ley general. el artículo 323 del código penal sanciona la discriminación por diversos factores y coloca al género dentro del rango de otros... si recuerdo el 5 de enero del 2017 se emitió la 30506, donde un decreto legislativo modifica la 
$1323 \ldots$... y se puso las razones de identidad de género como agravantes, pero como tenemos conocimientos por ausencia facultades se derogó parcialmente esa norma, dejando invisibles a la comunidad trans.

\section{¿Cuáles serían los retos de manera legal que una empresa pasaría si contrata dentro de su personal a una mujer trans?}

Empresas que son inclusivas... Actualmente existen varias, han aprendido que ser inclusivos les genera incluso una cantidad de consumidores con un poder adquisitivo importante además lo hace ver como una empresa moderna... si bien es cierto el tema de los trans era un tema muy cerrado, pero ahora se considera como una política avanzada porque estamos uniéndonos a la normatividad y jurisprudencia europea. en la clase A o B ellas adquieren mayor conocimiento si hay una empresa pro LGTB entre ellas las personas transgénero, va ser aceptada una cantidad más amplia de consumidores, entonces eso les genera fidelidad... por ello existen muchas empresas que ahora están haciendo la aplicación de estas políticas, pero tendríamos que ver allí, los retos pues que de manera legal pueda acoger a hombre o mujeres transgénero dentro de su empresa, además de promover el ambiente seguro... es decir que capacite también a su personal para que estos tengan conocimiento respecto a las personas trans a cómo llamarlos a cómo identificarlos a qué no decirles para causarles sensibilidad, esto de todas maneras es una inversión en información, ahora un punto más importante también sería de identificación, en el punto en el que cuento todos los días con reclamo y con denuncias. En los contratos establecen los nombres legales..., es decir el nombre que consta en el DNI y también el carnet o fotocheck se establece el nombre legal, esto vendría a ser un problema para las personas transgénero. debido a que muchas chicas, han realizado un proyecto de transformación completo. y tú la ves y son chicas mentalmente y ahora físicamente, entonces cuando van a trabajar a una empresa y en el momento de selección, una empresa inclusiva las acepta y los compañeros también. pero en el fotocheck dice por ejemplo 
Pedro, entonces las personas que vienen de afuera es decir los clientes, la ven y dicen, tú te llamas Pedro?... entonces es un tanto difícil, para el personal nuevo, para el personal no capacitado. entonces el tema de identificación es muy importante en las empresas... He tenido una experiencia con una empresa inclusiva que resolvió este problema de identificación en el trabajo, utilizando el nombre social invocando el artículo 32 del código civil, que señala la importancia del seudónimo, surge la misma importancia el nombre que en este caso para las personas trans han usado años... por ejemplo personas que han utilizado el nombre social desde muy jóvenes por 40 años o más..., entonces evocando este articulo 32 en los contrató, se toma el nombre social toma la importancia a modo de paliar y recibe la misma protección jurídica.., los fotocheck, los carnets, todos los implementos identificatorios tienen el nombre social, no como tal sino como el nombre legal, algunos dirán que no es legal pero invocando este artículo queda el nombre social en amparo jurisprudencial... Lo importante seria aplicar la seguridad de datos personales para esta información, el secreto personal para no exista el acceso libre a la información de personas transgénero, cosa que así no genera gastos a la empresa puede ser considerado el nombre y usando el nombre social en las empresas e incluso atribuyéndolo a los contratos y demás documentos... en síntesis, los retos legales serían. La información a su personal para crear un ambiente seguro..., el uso del seudónimo como el cual tiene la misma importancia que del nombre social y que se aplique en todos los documentos identificatorios y que se aplique a la seguridad de información de datos personales que no cualquiera pueda acceder.

\section{¿Cómo aportaría la aprobación de una ley de identidad de género en la carencia de oportunidades laborales para las mujeres trans?}

...Se reconocería la identidad de nombre y sexo en el todos los ámbitos incluido el laboral, si esta ley se aprueba contribuiría a incluirlo o como nombre legal y que traiga consigo todos los beneficios que eroga y por lo cual también obligaría a las empresas a que implementen 
el tema de identificación, nombre social y demás en virtud a la ley de identidad de género, entonces ya serian llamado por la identidad de género que se auto perciben, el seguro de salud los reconocería de la misma manera y por ende los beneficios sociales también y siendo así habría más oportunidad laboral, sin tanta discriminación Bull ying o violencia de todo tipo.., esto es un ganar personales que en general debido a que se generan mayores oportunidades de trabajo y las personas trans podrían contribuir con los impuestos al estado..

\section{Anexo 6. Entrevista a Lesly Quispe, Miembro del colectivo Féminas, líder de emprendimiento autónomo "Mascarillas Solidarias"}

Motivo de la entrevista: Conocer un poco sobre su liderazgo y organización en su propio negocio de apoyo social y su perspectiva como mujer trans con respecto a la problemática de carencia laboral en la comunidad de mujeres trans.

\section{¿De qué trata su emprendimiento?}

Lo que sucede es que a raíz del estado de emergencia a nivel mundial, yo siempre he realizado trabajo social a lo largo de mi vida, y como mencioné a raíz de la pandemia decidí, ver yo sola un pequeño negocio, pero este negocio no tenía un fin lucrativo ósea yo no quería llenar mis bolsillos con eso, yo quería seguir ayudando a aquellas personas más vulnerables como o hemos visto en los medio de comunicación, existen muchas carencias y necesidad, es por ello que decidí emprender y ponerle de nombre mascarillas solidarias, porque ahora las mascarillas son un símbolo de la necesidad en todas las personas del mundo, por el tema de salud y también símbolo de vulnerabilidad, y solidaria que a través de las ventas de estas mascarillas puedo seguir sosteniendo este emprendimiento para seguir apoyando.

\section{¿Hubo algunos obstáculos para empezar a emprender? ¿Cuáles fueron?}

Si... en primera instancia, ver si tiene acogida este pequeño proyecto por lo mismo que la gente estigmatiza mucho a las mujeres trans..., y nos relacionan con cosas negativas, siempre existe ese pequeño prejuicio... y otra barrera es buscar alguien de confianza que me ofrezca 
estas mascarillas, por lo mismo que también en las redes sociales se presentan estafadores... entonces creo que esos dos fueron los principales obstáculos.

\section{¿Existe una carencia laboral para la comunidad de mujeres trans?}

Así es, si existe... es una triste realidad por la cual muchas mujeres trans nos enfrentamos ..., me incluyo yo misma como mujer trans capacitada, me he presentado a varios trabajos con mi Curriculum., y siempre como nuestra identidad no coincide con nosotras como nos vemos físicamente..., siempre nos ponen un pero y nos dicen..., sí..., no te preocupes nosotros te llamamos y es, esa llamada que nunca llega lamentablemente... es por ello que muchas mujeres trans, optan por la peluquería o trabajo sexual..., y somos muy pocas las que nos atrevemos a emprender.

Anexo 7. Encuesta a Personas de 28 a 45 a más

Muestra: 54 personas

\section{Preguntas}

1. ¿Cuántos años tienes?

- $28-38(\mathbf{7 5 \%})$

- $39-44(\mathbf{1 3 \%})$

- $45+(\mathbf{1 1 . 1 \%})$

2. ¿Cuál es tu grado académico?

- Primaria (1.9\%)

- Secundaria (3.7\%)

- Técnico/Bachiller (55.6\%)

- Posgrado (35.2\%)

- Universitario en curso (1.9\%)

- $\operatorname{Mba}(\mathbf{1 . 9 \% )}$

- Maestría (1.9\%) 
3. ¿En qué situación laboral te encuentras actualmente?

- Dependiente (51.9\%)

- Independiente (24.1\%)

- Trabajo en mi propia empresa (14.8\%)

- No encuentro trabajo $(\mathbf{9 . 3 \%})$

4. ¿Formas parte o apoyas a la comunidad LGBTIQ+?

- Sí, formo parte de la comunidad LGBTIQ+ y también apoyo los ideales de la comunidad. (31.5\%)

- No formo parte de la comunidad LGBTIQ+, pero apoyo totalmente los ideales de la comunidad. (38.9\%)

- No formo parte y tampoco apoyo los ideales de la comunidad LGBTIQ+ (29.6 \%)

5. ¿Qué entiendes por identidad de género?

- Auto percibirse e Identificarse con el género femenino o masculino dependiendo del sexo con el que nos asignaron al nacer. (25.9\%)

- Auto percibirse e Identificarse con el género femenino o masculino independientemente del sexo con el que nos han asignado al nacer (70.4\%)

- Desconozco el significado. (3.7\%)

6. ¿Crees qué la orientación sexual y la identidad de género es lo mismo?

- Sí creo que es lo mismo (24.1\%)

- No creo que es lo mismo (66.7\%)

- Desconozco (9.3\%)

7. ¿En un contexto general, piensas qué la identidad de género y la orientación sexual de las personas que postulan a un puesto laboral debe influir en su proceso de evaluación para obtener un cupo laboral dentro de una empresa? 
- Sí debe influir (96.3\%)

- No debe influir (3.7\%)

8. ¿Consideras un inconveniente recibir un servicio técnico o profesional por una persona transgénero?

- Sí considero que es un inconveniente (7.4\%)

- No considero que sea un inconveniente $\mathbf{( 9 2 . 6 \% )}$

9. ¿Qué entiendes por mujer transexual?

- Un hombre que tiene actitudes femeninas y se ve viste como una mujer. $(24.5 \%)$

- Una persona que se auto percibe e identifica como una mujer y cuyo sexo asignado al nacer fue masculino. (75.5\%)

10. ¿Estás a favor que una mujer transexual tenga la misma oportunidad dentro del mercado laboral?

- Sí, estoy a favor. (92.6\%)

- No estoy a favor. $(\mathbf{0 . 0 \% )}$

- No sé, no opino (7.4\%)

11. ¿Crees que en el Perú existe discriminación hacia las personas transexuales?

- Sí, estoy de acuerdo. (83.3\%)

- No estoy de acuerdo. (7.4\%)

- No sé, no opino $(\mathbf{9 . 3 \%})$

12. ¿Estás de acuerdo con que se apruebe la "Ley de identidad de género"?

- Sí, estoy de acuerdo. (53.7\%)

- No estoy de acuerdo. (7.4\%)

- Desconozco la propuesta de la “Ley de identidad de género". (38.9\%) 
13. ¿Crees que la aprobación de la "Ley de identidad de género" ayudaría en el desarrollo del Perú?

- Sí estoy de acuerdo. (50\%)

- No estoy de acuerdo. (11.1\%)

- No sé, no opino. (38.9\%)

Anexo 8. Encuesta a Nuevos Emprendedores de pequeñas o medianas empresas de 24 a 45 años de edad.

Muestra: 31 personas

\section{Preguntas}

1. ¿Cuántos años tienes?

- $24-27(\mathbf{4 1 . 9 \% )}$

- $28-38(35.5 \%)$

- $39-44(\mathbf{1 6 . 1 \%})$

- $45(6.5 \%)$

2. Sexo

- Hombre (53.3\%)

- Mujer (46.7\%)

- Prefiero no decirlo $(\mathbf{0 . 0 \%})$

3. ¿El emprendimiento o empresa que lideras a que rubro pertenece?

- Sector Educación $\mathbf{( 9 . 7 \% )}$

- Sector Consumo Masivo (9.7\%)

- Sector Restaurantes (16.1\%)

- Sector tecnología (9.7\%)

- Sector Textil (16.1\%)

- Sector Industrial (6.5\%) 
- Sector retail (3.2\%)

- Sector Automotriz (3.2\%)

- Sector Telecomunicaciones $(\mathbf{6 . 5 \%})$

- Sector comercial de regalos y diseño (3.2\%)

- Construcción $(3.2 \%)$

- Papelería y artículos de oficina (3.2\%)

- Diseño (12.8\%)

4. ¿En la empresa o emprendimiento que lideras consideras tú la posibilidad de contratación de personas del sector LGBTIQ+?

- $\operatorname{Si}(\mathbf{8 0 . 6 \%})$

- No (12.9\%)

- Desconozco sobre las políticas inclusivas LGBTIQ+ $(\mathbf{6 . 5 \%})$

5. ¿En un contexto general, piensas que la identidad de género y la orientación sexual de las personas que postulan a un puesto laboral debe influir en su proceso de evaluación para obtener un cupo laboral dentro de una empresa?

- Sí debe influir (83.9\%)

- No debe influir (16.1\%)

6. ¿Crees que una empresa puede asumir con éxito la contratación de una persona mujer trans?

- Sí (90.3\%)

- $\quad$ No $(9.7 \%)$

7. ¿Consideras importante incorporar políticas inclusivas dentro de una empresa?

- No me parece importante incorporar políticas inclusivas LGBTIQ+ dentro de una empresa. (6.5\%) 
- Sí me parece importante incorporar políticas inclusivas LGBTIQ+ dentro de una empresa. (41.9\%)

- No tengo conocimientos sobre las políticas inclusivas LGBTIQ+ (51.6\%)

8. ¿Considerarías la posibilidad de incorporar a una persona trans dentro de tu pequeña o mediana empresa?

- $\quad$ Sí (67.7\%)

- $\quad$ No $(9.7 \%)$

- Tal vez (22.6\%)

9. Con respecto a la pregunta anterior ¿Por qué? (27 respuestas)

- Es una persona como cualquiera y lo único que debe importar es si está calificada o no

- Porque todos somos iguales sin discriminación

- Porque todos tenemos derecho a demostrar nuestro potencial, sin importar sexo, religión, creencias, etc.

- No vería el por qué no contratarlo (?)

- ¿Si la persona tiene experiencia y es competente, por qué no?

- ¡Por qué a la persona se le reconoce por su trabajo, no por lo es!

- Calidad de trabajador

- importa la experiencia que tenga

- Da igual su identidad de género y preferencias sexuales, a un trabajo se va a desarrollar tareas asignadas, no a discutir sobre la vida personal de los trabajadores.

- Depende de su personalidad

- Porque las habilidades y capacidades que tenga una persona no están relacionada con su género. 
- porque depende de su capacidad de trabajo

- no sé cómo lo tome mi clientela

- Por la mentalidad actual de la sociedad y los clientes.

- Depende del desempeño en el trabajo y no de su orientación sexual.

- Porque todos somos personas y si está calificada para el puesto podría entrar

- mis alumnos no tienen conocimiento sobre el tema

- ¿Por qué no? Es una persona como todos y si está calificada, me parece que no tiene nada de relevancia su sexo, género y orientación sexual.

- no es relevante

- Por qué se evalúa su capacidad profesional, no su vida sexual

- importa más su desempeño laboral

- porque todos tenemos los mismos derechos

- Eso no afecta sus capacidades

- No existe una influencia directa en el rendimiento profesional de una persona por su identidad sexual

- Su comportamiento

- Tomó más en cuenta el desempeño de la persona que su género, si esa persona no se desempeña o no la labora en su cargo como lo debe de hacer entonces lo despido sea quien sea (Mujer hombre u otro género)

- llamaría la atención en mi restaurante

10. ¿Crees que en el Perú existe discriminación hacia las personas trans?

- Sí(93.5 \%)

- No $(\mathbf{0 . 0 \%})$

- Tal vez (6.5\%) 


\title{
Anexo 9. Juicio de pares $\mathbf{n}^{\mathrm{a}} \mathbf{1}$
}

Lima 20 de noviembre 2020

\author{
Señores, \\ Carrera de Arte y Diseño Empresarial \\ Facultad de Humanidades \\ Universidad San Ignacio de Loyola
}

Por medio de la presente me dirijo a ustedes a fin de poder dar una opinión objetiva respecto al proyecto "Laborall.org" diseñado por la Bachiller Giovanna Graziela Ferrando Cáceres referido al Diseño de red social para la difusión de oportunidades laborales inclusivas para contribuir con el aumento de posibilidades de contratación de mujeres jóvenes trans del Perú.

Por lo tanto, al analizar y revisar el proyecto minuciosamente encuentro

que el mismo es Laborall.org, es un proyecto pertinente y necesario. Está bien estructurado atendiendo al problema y al público objetivo. Los objetivos del proyecto son bastante claros y tanto la propuesta de marca como toda la comunicación visual elaborada a partir de ella son coherentes. Laborall.org es una propuesta que a través del diseño busca sensibilizar sobre las peripecias que afrontan las personas trans para insertarse al mercado laboral y propone la creación de una red social para contribuir a su solución. Felicito la atención y el interés de la tesista en desarrollar proyectos inclusivos y empáticos con miras a mejorar la sociedad peruana contemporánea.

Atentamente

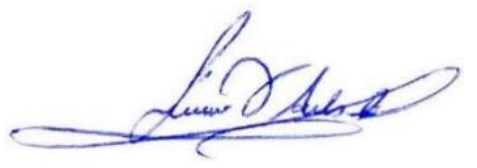

(Colocar firma escaneada)

Mg. Guillermina Victoria Avalos Carrillo 
Anexo 10. Juicio de pares $n^{\circ} 2$

Lima 22 de noviembre 2020

Señores,

Carrera de Arte y Diseño Empresarial

Facultad de Humanidades

Universidad San Ignacio de Loyola

Por medio de la presente me dirijo a ustedes a fin de poder dar una opinión objetiva respecto al proyecto "Laborall.org" diseñado por el Bachiller Giovanna Graziela Ferrando Cáceres referido al Diseño de red social para la difusión de oportunidades laborales inclusivas para contribuir con el aumento de posibilidades de contratación de mujeres jóvenes trans del Perú.

Por lo tanto, al analizar y revisar el proyecto minuciosamente encuentro que el mismo es importante, porque no sólo busca la mejora de la empleabilidad de las personas sea cual sea su género u opción sexual, sino es formar una comunidad, con soporte en diferentes aspectos para generar mayor inclusión, respeto y aceptación en los diferentes espacios donde se interactúa.

Atentamente

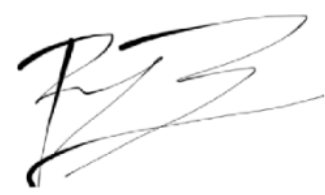

Mg. Rocio Alicia Caparó Becerra 


\section{Anexo 11. Juicio de pares n⿳3}

\section{Señores,}

CARRERA DE ARTE Y DISEÑO EMPRESARIAL

Facultad de Humanidades

Universidad San Ignacio de Loyola

Por medio de la presente me dirijo a ustedes a fin de poder dar una opinión objetiva respecto al proyecto "LABORALL.ORG" diseñado por el Bachiller Giovanna Graziela Ferrando Cáceres referido al Diseño de red social para la difusión de oportunidades laborales inclusivas para contribuir con el aumento de posibilidades de contratación de mujeres jóvenes trans del Perú.

Por lo tanto, al analizar y revisar el proyecto minuciosamente encuentro que el mismo es relevante porque piensa en traer al circuito económico a personas que por lo general, no son visibles antes los ojos del flujo económico; los revaloriza y les brinda una oportunidad de mejorar su nivel de vida. En contextos en los que las personas trans suelen estar dentro de una comunidad gueto, ser outsiders y no estar considerados siquiera en los censos nacionales, darles la oportunidad de pertenecer a círculos formales de la actividad económica es realmente sustancioso para nuestra sociedad.

Atentamente

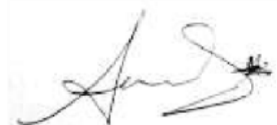

Sandra Leon Palomino - 40781336

Licenciada en Diseño Gráfico Empresarial

Especialista en UXUI Diseño de la Interacción 
Anexo 12. Juicio de pares $n^{\circ} 4$

Lima 20 de noviembre 2020

Señores,

Carrera de Arte y Diseño Empresarial

Facultad de Humanidades

Universidad San Ignacio de Loyola

Por medio de la presente me dirijo a ustedes a fin de poder dar una opinión objetiva respecto al proyecto "Laborall.org" diseñado por el Bachiller Giovanna Graziela Ferrando Cáceres referido al Diseño de red social para la difusión de oportunidades laborales inclusivas para contribuir con el aumento de posibilidades de contratación de mujeres jóvenes trans del Perú.

Por lo tanto, al analizar y revisar el proyecto minuciosamente encuentro que el mismo es un proyecto importante ya que es un primer paso hacia tener una sociedad más inclusiva. Una plataforma donde puedas participar sin tener un miedo al rechazo simplemente por tu orientación sexual ayudará a que muchas personas puedan encontrar un puesto de trabajo digno gracias a la forma en la que está diseñado brindando a parte de las vacantes, talleres, cursos, mentorías y charlas para que tanto las empresas como los postulantes sepan más sobre la importancia de ser una sociedad inclusiva y la igualdad.

Atentamente

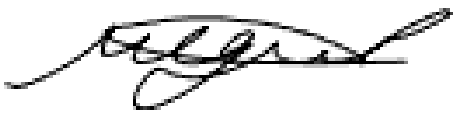

Miguel Alejandro Álvarez Solorzano

Head of Finance

Baitz Perú 


\section{Anexo 13. Juicio de pares $n^{0} 5$}

Lima 20 de Noviembre 2020

\section{Señores,}

Carrera de Arte y Diseño Empresarial

Facultad de Humanidades

Universidad San Ignacio de Loyola

Por medio de la presente me dirijo a ustedes a fin de poder dar una opinión objetiva respecto al proyecto "Laborall.org" diseñado por el Bachiller Giovanna Graziela Ferrando Cáceres referido al Diseño de red social para la difusión de oportunidades laborales inclusivas para contribuir con el aumento de posibilidades de contratación de mujeres jóvenes trans del Perú.

Por lo tanto, al analizar y revisar el proyecto minuciosamente encuentro que el mismo es importante, enfocado y pertinente. Desde mi punto de vista académico educativo y social, es un proyecto que va apoyar a la ciudadanía y que definitivamente podría tener un impacto importante en nuestra realidad peruana y mercado laboral. En la actualidad desde el sector estatal y privado no evidencia un apoyo o generación de políticas de inclusión para esta minoría de la comunidad LGBT, por lo que esta idea denota un alto nivel de predictibilidad para el éxito. También podría proponer que esto se convierta en una empresa o startup de corte social para que, de esta forma, el Perú se transforme poco a poco en un ecosistema más inclusivo y así estas leyes antidiscriminación se puedan promulgar de una forma más tranquila y natural. Finalmente, la tasa de colocación y empleabilidad que puedan tener personas trans se vea bastante empoderada y de forma positiva, de esta forma es que doy mi completa aprobación del proyecto.

\section{Muchas gracias}

Atentamente

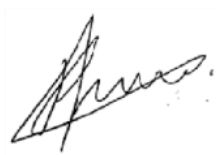

$\overline{M g . ~ D i e g o ~ C h a v e z ~ P e b e ~}$ 


\section{Bibliografía}

Adecco. (30 de noviembre de 2018). ¿Qué es el reclutamiento y selección de personal? Recuperado de: https://blog.adecco.com.mx/que-es-reclutamiento-seleccion-personal/

Charles, T. (1996). Identidad y Reconocimiento. Revista Internacional de Filosofía Política. (7). p10-11.

Cota, M. E. y García, B. K. (9 de febrero de 2009). Discriminación salarial por género en México. Problemas de Desarrollo, Revista Latinoamericana de economía de economía. Recuperado de: https://www.probdes.iiec.unam.mx/index.php/pde/article/view/7754/7229

EIDiario.es. (18 de junio de 2018). La OMS deja de considerar la transexualidad un trastorno mental. Recuperado de: https://www.eldiario.es/sociedad/oms-considerar-transexualidadenfermedad-incongruencia_1_2065796.html

García, L.P. (2005). Identidad de género: Modelos Explicativos. Escritos de la Psicología. (7). p75-76.

Gil. F. J. (2007). La evaluación de competencias laborales. Orientación y Formación en Competencias.10(4). p88-89.

Gómez, C. S. (2019). Políticas, prácticas y retos para la inclusión de la diversidad LGBTIQ, en tres centros laborales de Lima Metropolitana. (1a ed.). AC Industria Gráfica S. R. L.

Hurtado, M. F. (6 de mayo de 2015). Disforia de género en infancia y adolescencia: Guía de práctica clínica. Rev Esp Endocrinol Pediatra. Recuperado de: https://www.endocrinologiapediatrica.org/revistas/P1-E12/P1-E12-S510-A283.pdf Juarez Méndez, A. J. (2015). Discriminación y Estigmatización en la Transexualidad. Revista Publicando, 2(5), 160-170. Recuperado a partir de https://revistapublicando.org/revista/index.php/crv/article/view/96 
Machuca, R. M., Cocchella, L. R. y Gallegos, D. A. (2016). Nuestra voz persiste: diagnóstico de la situación de personas lesbianas, gay, bisexuales, transgénero, intersexuales y queer en el Perú. (la ed.) Tránsito - Vías de Comunicación Escénicas.

Méda, D. (noviembre, 2007) ¿Qué sabemos sobre el trabajo? Revista de Trabajo. Recuperado de: https://issuu.com/matilez/docs/revista_de_trabajo_-_a_o_3._nro_4_/17

Ministerio del Interior. (2018). Manual de Derechos Humanos aplicados a la función policial. (Resolución Ministerial N.o 952-2018-IN). Diario el Peruano

Mohanthy, J.N. (1994). Capas de Yoidad. En Olivé, L. y Salmerón, F., La identidad personal y colectiva: actas. (pp.23-25). Instituto de Investigaciones Filosóficas.

Secretaria de Gobernación (2016). ¿Qué es la identidad de género? Gobierno de México. Recuperado de: https://www.gob.mx/segob/articulos/que-es-la-identidad-de-genero

Molina, R. N., Guzmán, C. O. \& Martínez, G. A. (2015). Identidades transgénero y transfobia en el contexto mexicano: Una aproximación narrativa. Psicología e Identidades Transgénero en el contexto Iberoamericano.17(5). p 73-74.

Noseda, G.J., (2 de diciembre de 2012). Muchas Formas de transexualidad: diferencias de ser una mujer transexual y de ser una mujer transgénero. Revista de psicología. 21(2). p 9-10

Perú21. (01 de enero de 2012). ¿Qué papeles necesitas para trabajar? Recuperado de: https://peru21.pe/emprendimiento/papeles-necesitas-12736-noticia/

Petrus, J. (2013). International News Network. Un análisis de transgresiones de género en la producción audio-visual nicaragüense. Managua, Nicaragua: Instituto de Historia de Nicaragua. 
RPPNoticias. (13 de enero de 2020). Sueldo mínimo Estos han sido los aumentos desde Fujimori a Kuczynski. Recuperado de: https://rpp.pe/economia/economia/sueldo-minimoestos-han-sido-los-aumentos-desde-fujimori-a-kuczynski-noticia-1239331?ref=rpp

Sue,D. (1996). Psicopatología: comprendiendo la conducta anormal. Recuperado de: http://biblioteca.udla.edu.ec/client/es_EC/default/search/detailnonmodal/ent:\$002f\$002fSD_I LS\$002f0\$002fSD_ILS:2599/ada?qu=Sue\%2C+David\&te=ILS\&ps=300

Silva, A., Amat, H., León, F., García, G., Castillo, J., Vilela, J., Salazar, X. (2020). Informe Anual del observatorio de derechos LGBT 2019. Recuperado de: http://iessdeh.org/usuario/ftp/Informe_observatorio_2020.pdf?fbclid=IwAR0rSENZngRM8isz V7RNz0WP3g7yeh4rb4eOz8P4daqU2eHAwZalC7c1y3s

Ureña, A., Ferrari, A. Blanco, D y Valdecasa, E. (2011). Las Redes Sociales en Internet. Observatorio Nacional de las telecomunicaciones y de la SI. Recuperado de: https://www.ontsi.red.es/sites/ontsi/files/redes_sociales-documento_0.pdf Whittle, Stephen \& Turner, Lewis \& Al-Alami, Maryam \& Contributors, \& Rundall, Em \& Thom, Ben. (2007). Engendered Penalties: Transgender and Transsexual People's Experiences of Inequality and Discrimination Recuperado de: https://www.researchgate.net/publication/265032393_Engendered_Penalties_Transgender_an d_Transsexual_People's_Experiences_of_Inequality_and_Discrimination 
